\title{
Article \\ Stabilization and Carbonization of PAN Nanofiber Mats Electrospun on Metal Substrates
}

\author{
Jan Lukas Storck ${ }^{1}\left(\right.$, Bennet Brockhagen ${ }^{1}$, Timo Grothe ${ }^{1}{ }^{10}$, Lilia Sabantina ${ }^{1}$, Bernhard Kaltschmidt ${ }^{2}$, \\ Khorolsuren Tuvshinbayar ${ }^{1}$, Laura Braun ${ }^{1}$, Ewin Tanzli ${ }^{1}$, Andreas Hütten ${ }^{2}$ and Andrea Ehrmann ${ }^{1, *}$ \\ 1 Faculty of Engineering and Mathematics, Bielefeld University of Applied Sciences, 33615 Bielefeld, Germany; \\ jan_lukas.storck@fh-bielefeld.de (J.L.S.); bennet.brockhagen@fh-bielefeld.de (B.B.); \\ timo.grothe@fh-bielefeld.de (T.G.); lilia.sabantina@fh-bielefeld.de (L.S.); \\ Khorolsuren.Tuvshinbayar@fh-bielefeld.de (K.T.); laura.braun@fh-bielefeld.de (L.B.); \\ ewin.tanzli@fh-bielefeld.de (E.T.) \\ 2 Thin Films and Physics of Nanostructures, Bielefeld University, 33615 Bielefeld, Germany; \\ b.kaltschmidt@uni-bielefeld.de (B.K.); andreas.huetten@uni-bielefeld.de (A.H.) \\ * Correspondence: andrea.ehrmann@fh-bielefeld.de
}

Citation: Storck, J.L.; Brockhagen, B.; Grothe, T.; Sabantina, L.; Kaltschmidt B.; Tuvshinbayar, K.; Braun, L.; Tanzli, E.; Hütten, A.; Ehrmann, A. Stabilization and Carbonization of PAN Nanofiber Mats Electrospun on Metal Substrates. C 2021, 7, 12. https://doi.org/10.3390/c7010012

Received: 30 November 2020

Accepted: 23 January 2021

Published: 27 January 2021

Publisher's Note: MDPI stays neutral with regard to jurisdictional claims in published maps and institutional affiliations.

Copyright: (c) 2021 by the authors. Licensee MDPI, Basel, Switzerland. This article is an open access article distributed under the terms and conditions of the Creative Commons Attribution (CC BY) license (https:// creativecommons.org/licenses/by/ $4.0 /)$.

\begin{abstract}
Polyacrylonitrile (PAN) nanofiber mats are typical precursors for carbon nanofibers. They can be fixed or even elongated during stabilization and subsequent carbonization to gain straight, mechanically robust carbon nanofibers. These processes necessitate additional equipment or are-if the nanofiber mats are just fixed at the edges-prone to resulting in the specimens breaking, due to an uneven force distribution. Hence, we showed in a previous study that electrospinning PAN on aluminum foils and stabilizing them fixed on these substrates, is a suitable solution to keep the desired morphology after stabilization and incipient carbonization. Here, we report on the influence of different metallic and semiconductor substrates on the physical and chemical properties of the nanofiber mats after stabilization and carbonization at temperatures up to $1200{ }^{\circ} \mathrm{C}$. For stabilization on a metal substrate, an optimum stabilization temperature of slightly above $240{ }^{\circ} \mathrm{C}$ was found, approached with a heating rate of $0.25 \mathrm{~K} / \mathrm{min}$. Independent from the substrate material, SEM images revealed less defect fibers in the nanofiber mats stabilized and incipiently carbonized on a metal foil. Finally, high-temperature carbonization on different substrates is shown to allow for producing metal/carbon nano-composites.
\end{abstract}

Keywords: polyacrylonitrile (PAN); nanofibers; electrospinning; aluminum; copper; tin; titanium; silicon wafer; steel; stabilization and carbonization

\section{Introduction}

Carbon nanofibers are often prepared from electrospun polyacrylonitrile (PAN) nanofibers or nanofiber mats [1-3]. Such carbon nanofiber mats are used in a broad range of applications, such as water filtration [4], air filtration [5], the electrodes of superconductors [6], sensors [7], etc., often doped or coated with diverse nanoparticles to reach the desired properties [8]. Generally, PAN can be electrospun with needle-based or needleless electrospinning techniques, purely, blended with other polymers or doped with nanoparticles, and even as Janus nanofibers [9-11].

PAN as a carbon precursor has two main advantages: on the one hand, it has a high carbon yield [12]; on the other hand, it can be electrospun from dimethyl sulfoxide (DMSO), a solvent which is much less toxic than many other typical solvents used for electrospinning [13].

Carbonization of PAN nanofiber mats is usually performed by a two-step process. Firstly, stabilization at an intermediate temperature around $280^{\circ} \mathrm{C}$ in air results in oxidation, aromatization, cyclization, dehydrogenation and crosslinking [14,15]. This process is not only a necessary prerequisite of the subsequent carbonization step, but will strongly 
influence the final carbon nanofiber properties. Thus, a great deal of effort is made by diverse research groups to optimize the stabilization parameters, such as the heating rate, temperature and duration of isothermal treatment [3,16-18]. Another important point, often not explicitly mentioned in the literature, is the mechanical treatment during stabilization. If the nanofiber mat can freely move during this process, even with the slowest heating rates, the fibers will deform due to the relief of the internal stress introduced during electrospinning [19]. To avoid this usually undesired shrinking and bending of the nanofibers, they can be stretched by applying a mass or fixed on two or along all four sides [3,20-25]. Here, often the problem occurs that the nanofiber mats break due to uneven force distributions in the mats.

To avoid this problem, we showed in previous studies that electrospinning on an aluminum foil and stabilizing without previously detaching the nanofiber mat from the metal foil can be used as a simple method to retain the nanofiber morphology during stabilization [26]. These first results were extended to investigations of stabilization and incipient carbonization on different aluminum foils, applying a broad range of process parameters, showing that the substrate thickness or surface did not influence the stabilization and carbonization results, while the stabilization heating rates had a significant impact on the stabilized and carbonized nanofibers [27].

Here, broadening the parameters under investigation, we report on substrates from different materials, namely metal foils and a silicon wafer, used for stabilization and carbonization up to $1200{ }^{\circ} \mathrm{C}$, depending on the temperature range accessible with the respective substrate.

\section{Materials and Methods}

Electrospinning was performed with a wire-based electrospinning machine "Nanospider Lab" (Elmarco, Liberec, Czech Republic). The spinning parameters were as follows: voltage $80 \mathrm{kV}$, resulting current $\sim 0.1 \mathrm{~mA}$, nozzle diameter $0.9 \mathrm{~mm}$, electrode-substrate distance $240 \mathrm{~mm}$, carriage speed $100 \mathrm{~mm} / \mathrm{s}$, substrate speed $0 \mathrm{~mm} / \mathrm{min}$, relative humidity $32 \%$, and temperature in the spinning chamber $22-23{ }^{\circ} \mathrm{C}$. These parameters are identical to those used in [27] to enable comparison. The spinning duration is usually $30 \mathrm{~min}$, if not defined differently.

For the spinning solution, $16 \mathrm{wt} \%$ X-PAN (copolymer with 6\% methyl methacrylate, X-PAN, Dralon, Dormagen, Germany) were dissolved in DMSO (min. 99.9\%, S3 chemicals, Bad Oeynhausen, Germany) by stirring for $2 \mathrm{~h}$ at room temperature. Again, this solution was identical to the previous one from Ref. [27].

The following substrates were glued via double-sided adhesive tape (Tesa SE, Norderstedt, Germany) onto the polypropylene (PP) nonwoven substrates (Elmarco, Liberec, Czech Republic):

- $\quad$ Aluminum foil, thickness $35 \mu \mathrm{m}$ (Vireo.de, Merseburg, Germany)

- $\quad$ Copper foil thin, thickness $35 \mu \mathrm{m}$ (Blechmaennle-de, Rottenburg, Germany)

- Copper foil middle, thickness $51 \mu \mathrm{m}$ (Blechmaennle-de, Rottenburg, Germany)

- Copper foil thick, thickness $100 \mu \mathrm{m}$ (Blechmaennle-de, Rottenburg, Germany)

- Copper foil tin-coated, thickness $35 \mu \mathrm{m}$ (CMC Klebetechnik GmbH, Frankenthal, Germany)

- $\quad$ Titanium sheet, thickness $100 \mu \mathrm{m}$ (Evek GmbH, Mühlheim an der Ruhr, Germany)

- Stainless steel V2a sheet, thickness $500 \mu \mathrm{m}$ (Kannegiesser GmbH, Vlotho, Germany)

- $\quad$ Steel st235jr sheet, thickness $500 \mu \mathrm{m}$ (Kannegiesser GmbH, Vlotho, Germany)

- Silicon (100) wafer, thickness $510 \mu \mathrm{m}$ (Science Service GmbH, Munich, Germany)

As a reference, a pure PAN nanofiber mat directly electrospun on the PP substrate was used. After electrospinning, the nanofiber mat/substrate composites were stabilized in a muffle oven B150 (Nabertherm, Lilienthal, Germany), approaching a temperature of typically $280^{\circ} \mathrm{C}$ with a usual heating rate of $0.25 \mathrm{~K} / \mathrm{min}$, followed by isothermal treatment for $1 \mathrm{~h}$. These were the most suitable parameters according to the results of [27]. Different treatment parameters are mentioned in the respective experiments. 
Afterwards, a furnace CTF 12/TZF 12 (Carbolite Gero Ltd., Sheffield, UK) was used for carbonization, approaching temperatures of $500{ }^{\circ} \mathrm{C}$ to $1200{ }^{\circ} \mathrm{C}$ (max. possible oven temperature) with a heating rate of typically $10 \mathrm{~K} / \mathrm{min}$ in a nitrogen gas flow of $100 \mathrm{~mL} / \mathrm{min}$ (STP), again followed by isothermal treatment for $1 \mathrm{~h}$. Typical samples sizes were between $2 \mathrm{~cm} \times 2 \mathrm{~cm}$ and $3 \mathrm{~cm} \times 3 \mathrm{~cm}$.

Additional measurements by differential scanning calorimetry (DSC) or thermogravimetric analysis (TGA), as often used to understand the heat treatment procedure better [3], are here not possible due to the large masses of the substrates which would strongly superpose the temperature-dependent effects in the nanofiber mats.

Photographs of the samples after the different process steps were taken with a smartphone camera Xiaomi Redmi Note 9 Pro. Chemical investigation was performed by a Fourier-transform infrared (FTIR) spectroscope Excalibur 3100 (Varian Inc., Palo Alto, CA, USA) in attenuated total reflection mode (ATR-FTIR), using a wavenumber range from $4000-700 \mathrm{~cm}^{-1}$. The spectra were averaged over 32 scans and corrected for atmospheric noise. Confocal laser scanning microscopy (CLSM) was performed with a VK-9700 (Keyence, Neu-Isenburg, Germany).

SEM images were taken by a scanning electron microscope (SEM) Helios NanoLab DualBeam 600 (FEI Company, Hillsboro, OR, USA) after sputter coating with $10 \mathrm{~nm}$ ruthenium, applying a voltage of $5 \mathrm{kV}$ and a beam current of $0.34 \mathrm{nA}$.

Color investigations of the nanofiber mats after stabilization and incipient carbonization were performed using a spectrophotometer sph900 (ColorLite GmbH, KatlenburgLindau, Germany). Comparative measurements were taken against a reference white MA38 BAM-Standard 1E2187c, serial no. 45010.

\section{Results and Discussion}

Firstly, the influence of the substrate material on the stabilization process was investigated. Figure 1 shows photographs of PAN nanofiber mats, electrospun for $1 \mathrm{~h}$, after stabilization on different substrates at $280^{\circ} \mathrm{C}$, approached with a heating rate of $0.25 \mathrm{~K} / \mathrm{min}$.

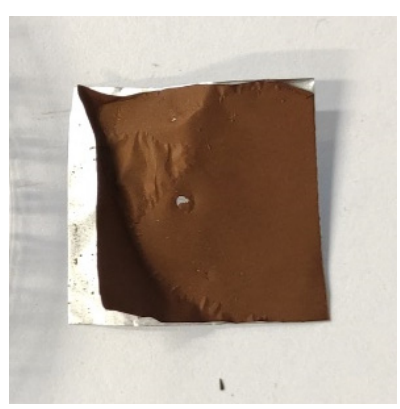

(a)

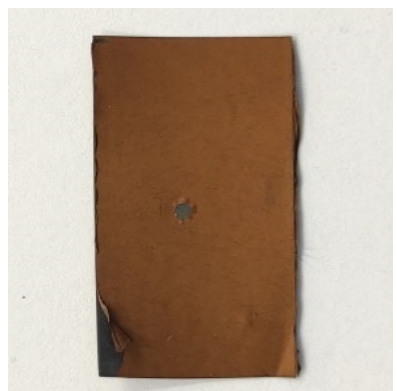

(e)

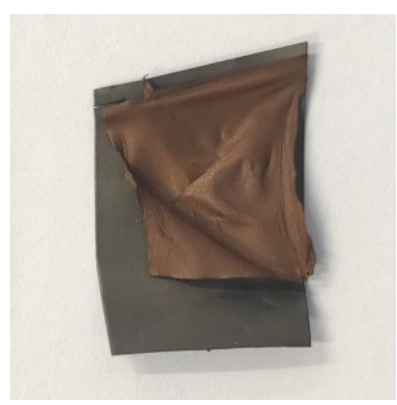

(b)

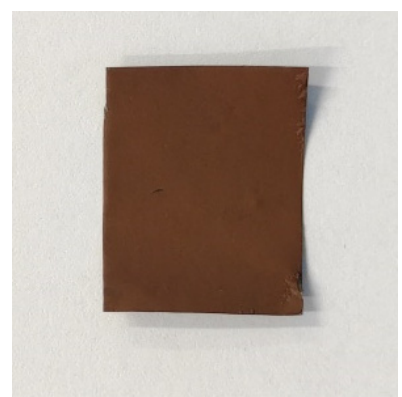

(f)

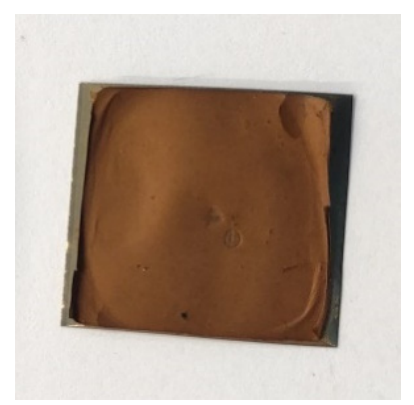

(c)

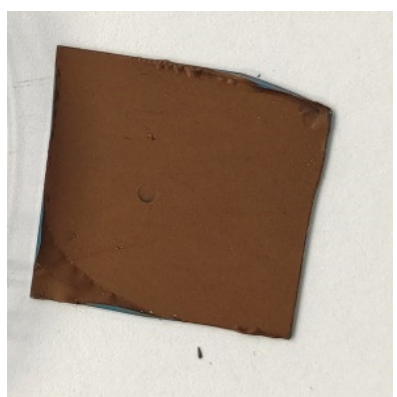

(g)

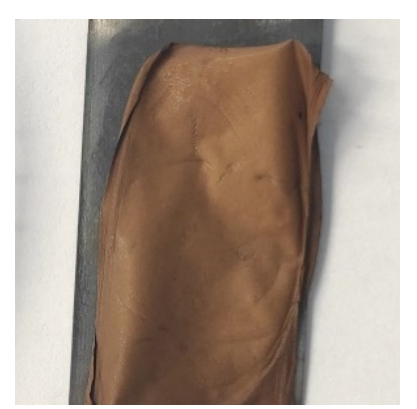

(d)

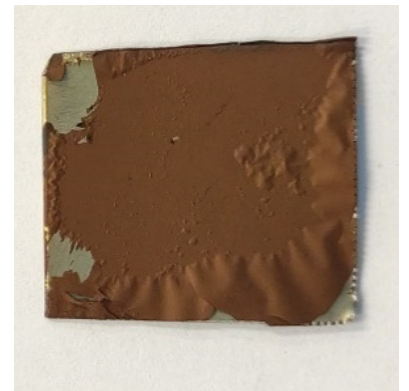

(h)

Figure 1. Cont. 


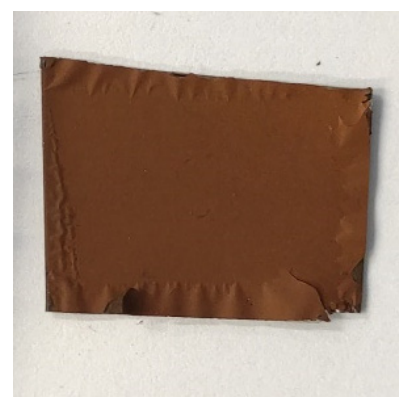

(i)

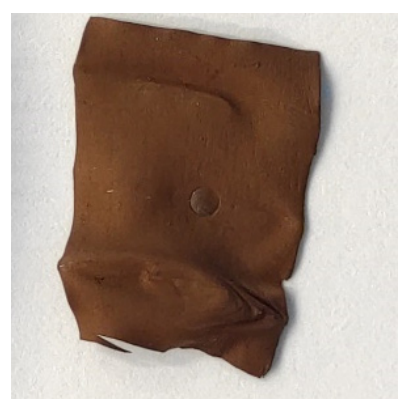

(j)

Figure 1. Nanofiber mats, stabilized for $1 \mathrm{~h}$ at $280^{\circ} \mathrm{C}$, approached by a heating rate of $0.25 \mathrm{~K} / \mathrm{min}$ : (a) aluminum; (b) copper foil tin-coated; (c) titanium sheet; (d) copper foil thick; (e) copper foil middle; (f) copper foil thin; (g) Si wafer; (h) stainless steel V2a; (i) steel st235jr; (j) pure Polyacrylonitrile (PAN) nanofiber mat.

Generally, the brownish color, which can be used to estimate the degree of stabilization [3], is similar in all cases, but nevertheless shows slight differences. The PAN nanofiber mat stabilized without substrate (Figure 1j) may show a slightly darker color; this will be investigated later on. One possible explanation is a more pronounced stabilization process; however, previous research [26] revealed that the darker color here can be explained by the shrinking of the nanofibers which were not fixed during stabilization.

To examine this reliably, Figure 2a shows FTIR graphs of the nanofiber mats stabilized on different substrates. For the copper substrates, only the middle foil thickness is shown since FTIR images of the others are approximately identical. In all graphs, the typical peaks of stabilized PAN are visible $[3,18,26]$. The peaks at $1582 \mathrm{~cm}^{-1}$ and $1660 \mathrm{~cm}^{-1}$ indicate $\mathrm{C}=\mathrm{N}$ and $\mathrm{C}=\mathrm{C}$ stretching vibrations, respectively. The peak at $1360 \mathrm{~cm}^{-1}$ stems from $\mathrm{C}-\mathrm{H}$ bending and $\mathrm{C}-\mathrm{H}_{2}$ wagging, while the small peak near $800 \mathrm{~cm}^{-1}$ can be attributed to aromatic $\mathrm{C}-\mathrm{H}$ vibrations after the oxidative dehydrogenation aromatization. The oxygen crosslinking between the polymer chains results in $\mathrm{C}-\mathrm{O}$ and $\mathrm{C}-\mathrm{O}-\mathrm{C}$ vibrations, visible in the ranges between $1230-1250 \mathrm{~cm}^{-1}$ and $1050-1090 \mathrm{~cm}^{-1}$.

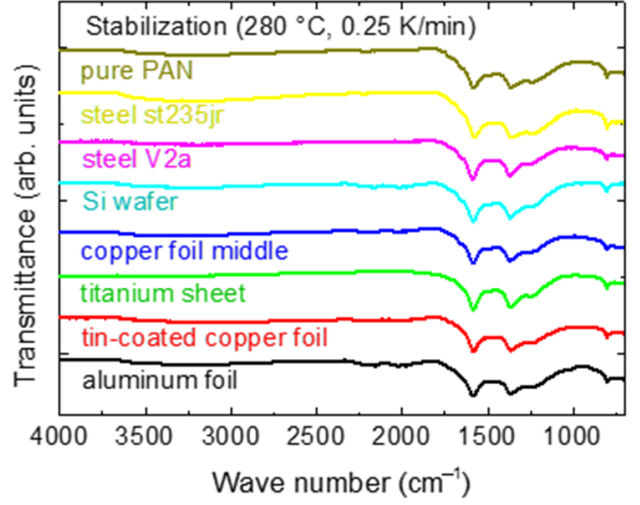

(a)

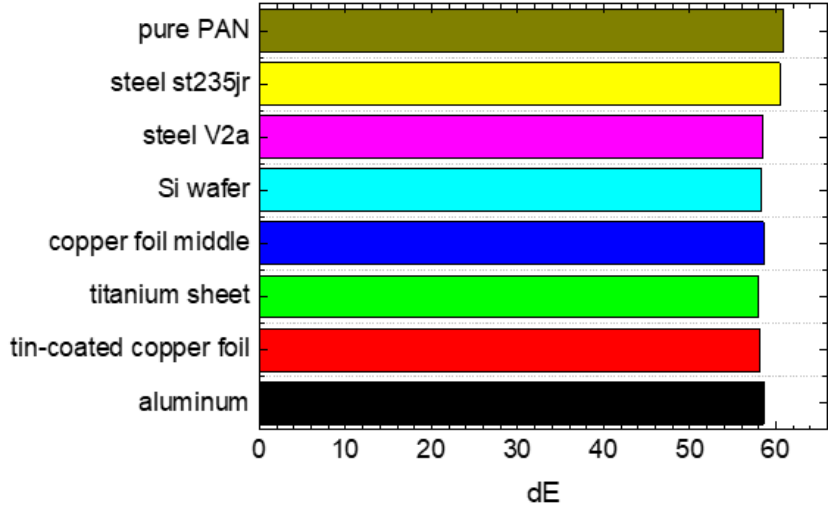

(b)

Figure 2. (a) FTIR measurements of nanofiber mats from Figure 1. Lines are vertically shifted for clarity. (b) Color differences $\mathrm{dE}$ of the samples from Figure 1.

While these wave number ranges do not show differences for different substrates, the slopes of the curves differ at small wave numbers. This, however, can be attributed to the metal substrates which become visible in this range [26]. From the FTIR data, it can be concluded that no significant chemical differences are visible for stabilization on different substrates. 
The color differences $\mathrm{dE}$, depicted in Figure $2 b$, are a good indicator for the stabilization process since samples become darker during stabilization, and at the same time can be expected to be slightly smaller for samples stabilized under identical thermal conditions, but fixed on a substrate, as compared to samples stabilized freely [3].

Here, however, no significant differences are visible between the samples stabilized on a substrate and the reference sample, stabilized without fixation. This may be due to the relatively small heating rate of $0.25 \mathrm{~K} / \mathrm{min}$ applied here, as opposed to the heating rate of $1 \mathrm{~K} / \mathrm{min}$ applied in the previous investigation [3]. Apparently, morphological differences between samples stabilized freely and fixed are reduced for lower heating rates.

To investigate this aspect further, Figure 3 depicts exemplary SEM images of nanofiber mats spun on the pure PP substrate and on a thin copper substrate, taken after electrospinning and after stabilization. Besides some arbitrarily visible thick fibers after electrospinning on the copper substrate (Figure 3c), comparing both images after stabilization under identical thermal conditions (Figure 3b,d) shows a much smaller influence of the substrate on the nanofiber morphology than in previous investigations, using different ways of fixation $[3,26]$.

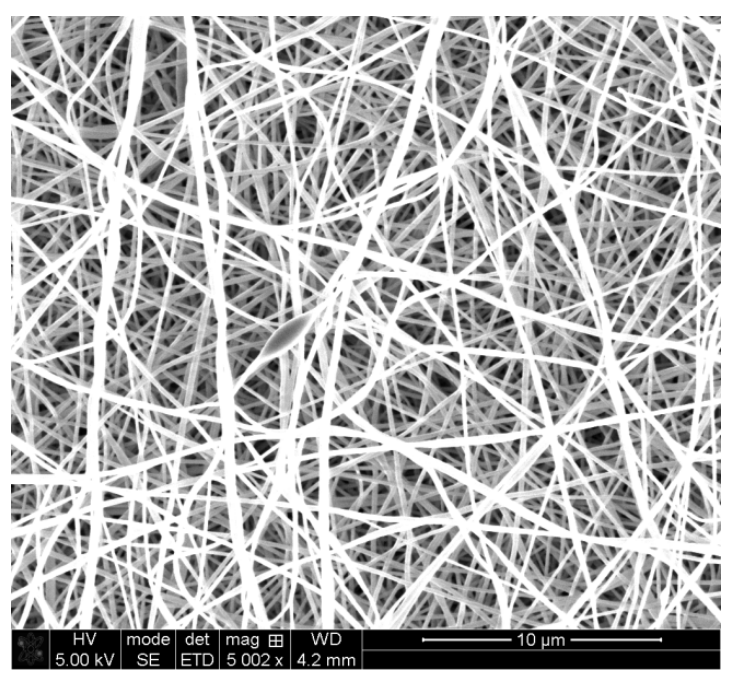

(a)

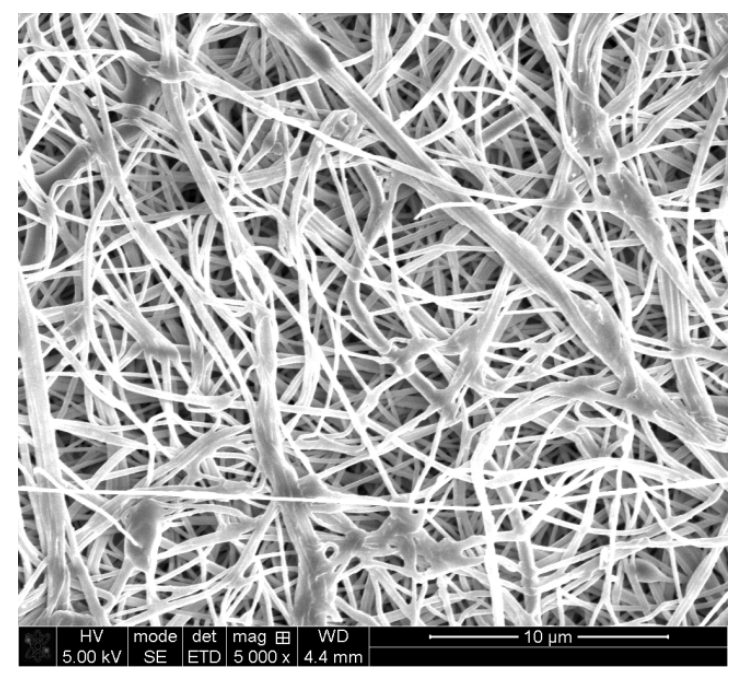

(c)

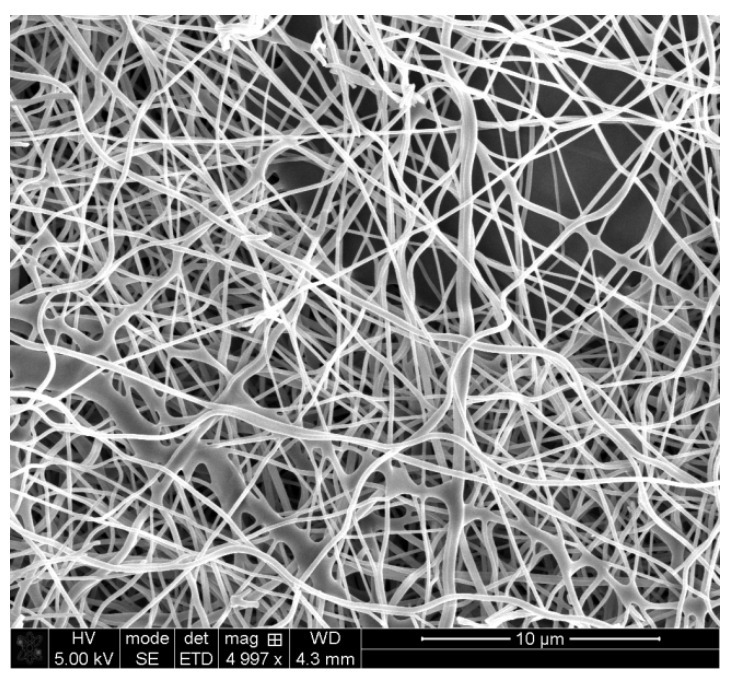

(b)

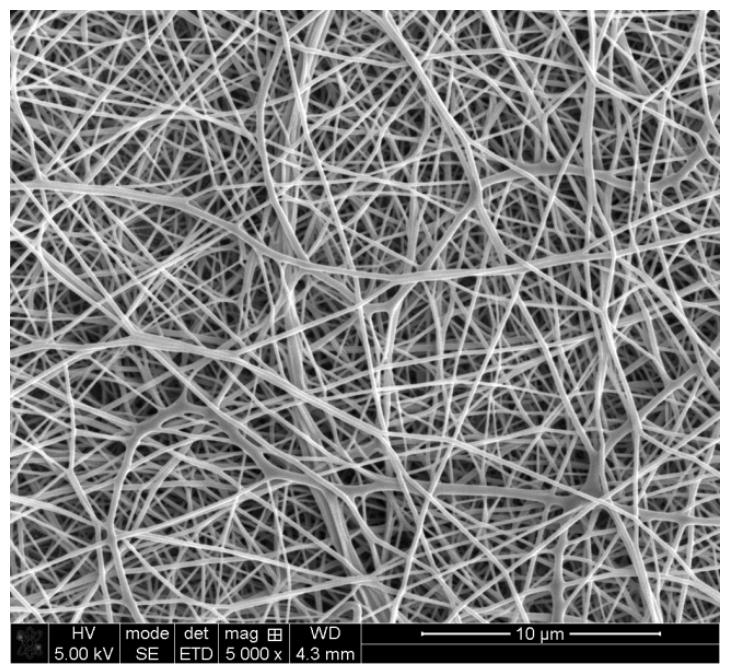

(d)

Figure 3. (a) Pure PAN nanofiber mat after electrospinning; (b) pure PAN nanofiber mat after stabilization at $280{ }^{\circ} \mathrm{C}$, approached with $0.25 \mathrm{~K} / \mathrm{min}$; (c) PAN nanofiber mat on thin copper foil after electrospinning; (d) PAN nanofiber mat on thin copper foil after stabilization at $280{ }^{\circ} \mathrm{C}$, approached with $0.25 \mathrm{~K} / \mathrm{min}$. 
This finding supports the importance of carefully choosing the heating rate, besides the possibility to use a metal substrate for fixation of the nanofiber mat during stabilization.

Next, Figure 4 shows series of stabilization tests at different temperatures, approached with a heating rate of $0.25 \mathrm{~K} / \mathrm{min}$, on two exemplarily chosen substrates.

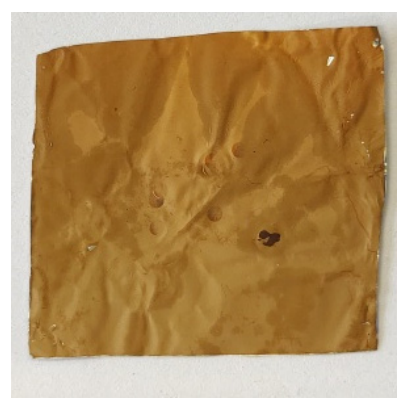

(a)

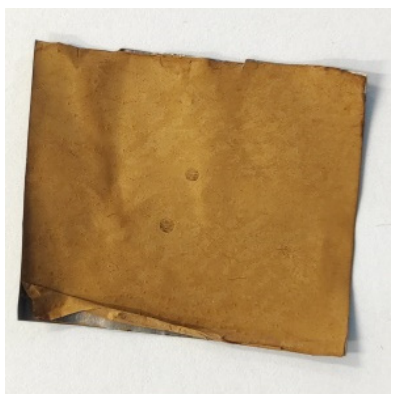

(e)

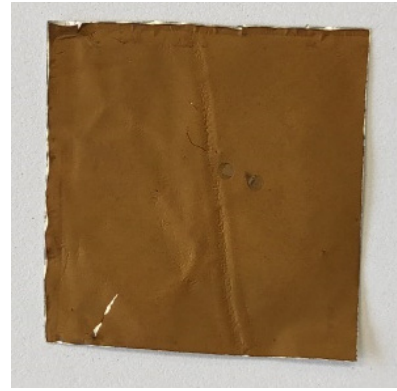

(b)

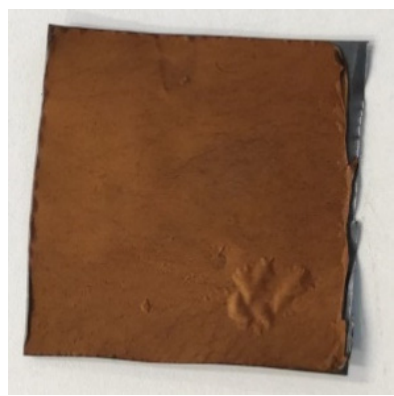

(f)

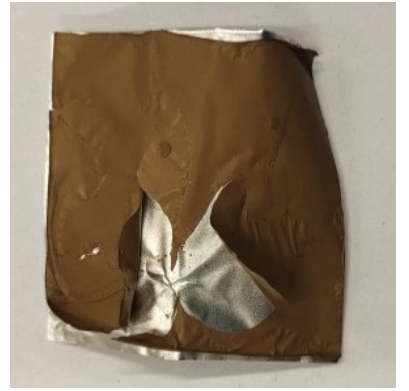

(c)

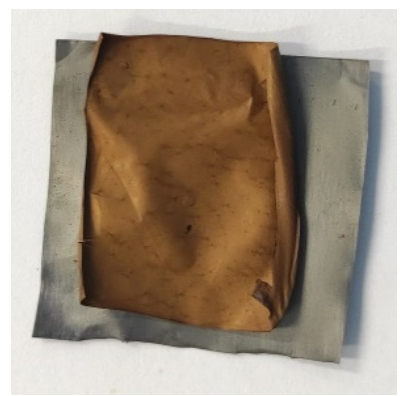

$(\mathrm{g})$

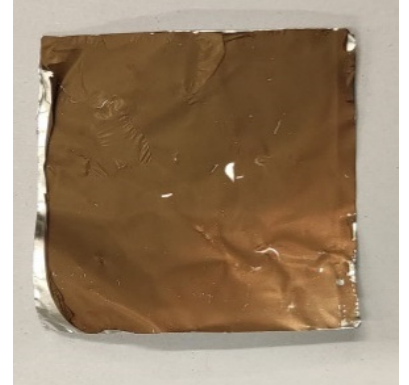

(d)

Figure 4. Nanofiber mats, stabilized for $1 \mathrm{~h}$ at different temperatures, approached by a heating rate of $0.25 \mathrm{~K} / \mathrm{min}$, on (a) aluminum at $200{ }^{\circ} \mathrm{C}$; (b) $240{ }^{\circ} \mathrm{C}$; (c) $320{ }^{\circ} \mathrm{C}$; (d) $360{ }^{\circ} \mathrm{C}$; (e) copper foil tin-coated at $200{ }^{\circ} \mathrm{C}$; (f) $240{ }^{\circ} \mathrm{C}$; (g) $320^{\circ} \mathrm{C}$.

For the aluminum foil, the results are similar to the findings in a previous study on pure PAN nanofiber mats [3]. On the one hand, higher temperatures lead to darker colors, indicating more complete stabilization. On the other hand, less damage occurs at lower temperatures. Apparently, in spite of the mechanically supporting substrate, there is still the need to balance mechanical and chemical properties. On the tin-coated copper foil, similar colors indicate similar grades of stabilization, while the higher stabilization temperatures resulted in detachment of the nanofiber mats.

This is why Figure 5a depicts FTIR measurements of PAN nanofibers mats stabilized on the aluminum foil at different temperatures for $1 \mathrm{~h}$, approached with a heating rate of $0.25 \mathrm{~K} / \mathrm{min}$. By comparing these graphs, it becomes apparent that at $200^{\circ} \mathrm{C}$ nearly no typical peaks of stabilized PAN are visible, while already at a temperature of $240{ }^{\circ} \mathrm{C}$, the characteristic double-peak around $1500 \mathrm{~cm}^{-1}$ can be recognized. Although the shapes of the curves of stabilization temperatures between $240{ }^{\circ} \mathrm{C}$ and $360^{\circ} \mathrm{C}$ differ slightly, it is not possible to detect a quantitative difference between them.

This contrasts with a former investigation of the stabilization process of pure PAN nanofiber mats, where FTIR graphs clearly showed full stabilization only at $280-300{ }^{\circ} \mathrm{C}$ [3]. This contrast, however, cannot be attributed to the substrates, but is a consequence of the different heating rates. In the previous study [3], relatively high heating rates of $2 \mathrm{~K} / \mathrm{min}$ were chosen for the comparison of different stabilization temperatures. The heating rate was found to play a crucial role during stabilization pure nanofiber mats [3] as well as nanofiber mats on metal substrates [27]. 


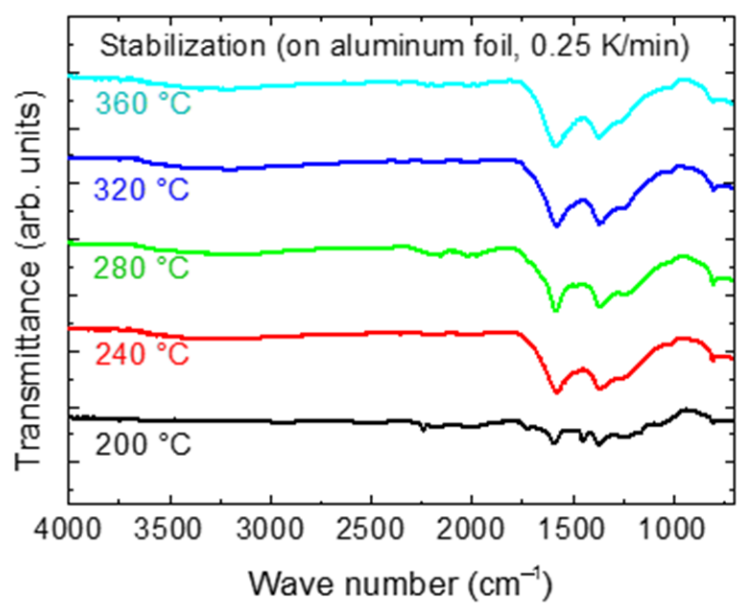

(a)

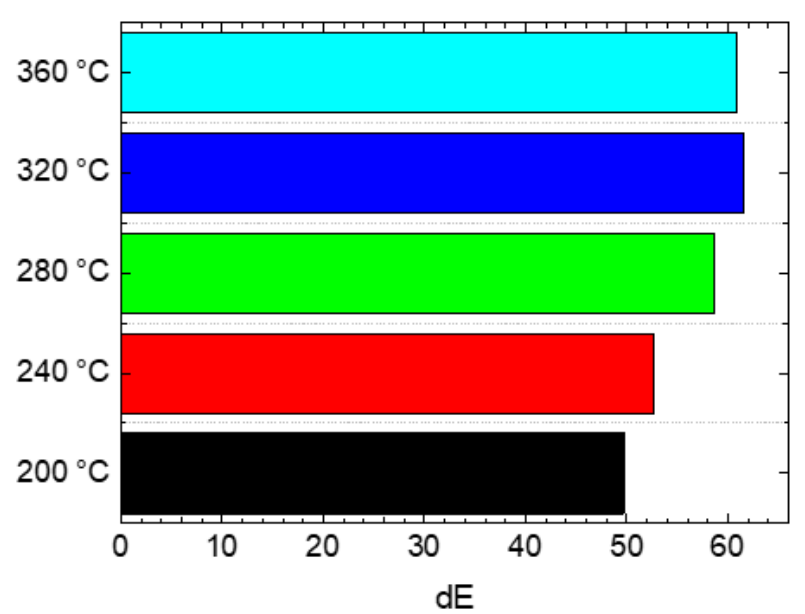

(b)

Figure 5. (a) FTIR measurements of nanofiber mats stabilized on aluminum foil at different temperatures for $1 \mathrm{~h}$. Lines are vertically shifted for clarity. (b) Color differences $\mathrm{dE}$ of the same samples.

The color differences $\mathrm{dE}$ depicted in Figure $5 \mathrm{~b}$ are clearly different for the lower temperatures, but saturate from a stabilization temperature of $280^{\circ} \mathrm{C}$, showing that stabilization is completed at $280^{\circ} \mathrm{C}$.

Comparing both results shows that, for the heating rate chosen here of only $0.25 \mathrm{~K} / \mathrm{min}$, a stabilization temperature between 240 and $280{ }^{\circ} \mathrm{C}$ seems to be ideal. To enable comparison with previous studies of our group and others, however, most experiments here were conducted with a stabilization temperature of $280^{\circ} \mathrm{C}$ which is the typical value often reported in the literature.

The influence of the substrate on the carbonization process was thus investigated, applying the optimum heating rate of $0.25 \mathrm{~K} / \mathrm{min}$ as well as the typical temperature of $280^{\circ} \mathrm{C}$ during stabilization. Carbonization was performed at different temperatures, up to maximum values next to the melting temperature of copper-based metal substrates as well as up to a temperature of $1200{ }^{\circ} \mathrm{C}$ on the $\mathrm{Si}$ wafer, steel and titanium sheet, respectively.

Figure 6 depicts the results of incipient carbonization at a temperature of $500{ }^{\circ} \mathrm{C}$ for $1 \mathrm{~h}$, approached with a typical heating rate of $10 \mathrm{~K} / \mathrm{min}$. These images reveal already large differences between the different substrates. On the one hand, some of the nanofiber mats are still partly or even fully attached, while others are completely detached. On the other hand, the colors are quite different. As explained above, it could be expected that the pure nanofiber mat (Figure 6j) shows the darkest color after incipient carbonization since it shrank strongest during stabilization. Nevertheless, especially the nanofiber mat on the $\mathrm{Si}$ wafer shows a similarly dark color. On the thick copper foil (Figure 6d), most of the nanofiber mat is already detached, and only parts of the nanofiber mat are still stuck on the substrate. On the middle and thin copper foils (Figure 6e,f), the nanofiber mats are fully detached, but not torn, as it is the case for the thick substrate.

To investigate these findings in more detail, Figure 7a depicts FTIR graphs of these samples. Again, FTIR images of the copper substrates are approximately identical. At first glance, these graphs look quite similar to Figure 2, measured after stabilization. Indeed, it is well-known that carbonization is only started at a temperature of $500{ }^{\circ} \mathrm{C}$ [27]. Only the C-O vibrations in the wave number range of $1230-1250 \mathrm{~cm}^{-1}$ are more pronounced now, broadening the maximum at $1360 \mathrm{~cm}^{-1}$. Generally, no chemical differences are visible, comparing the different substrates. 


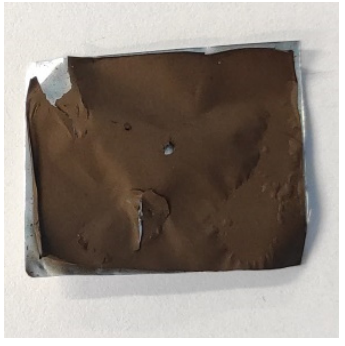

(a)

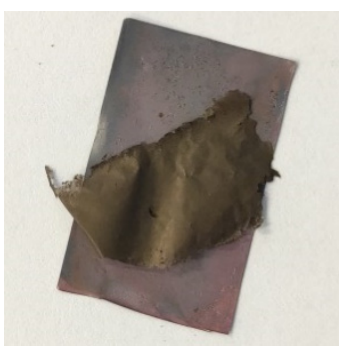

(e)

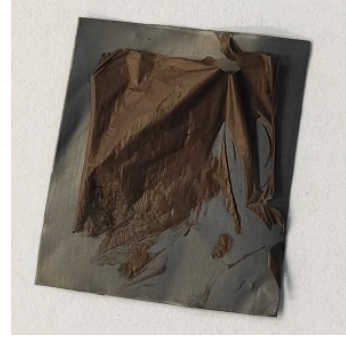

(b)

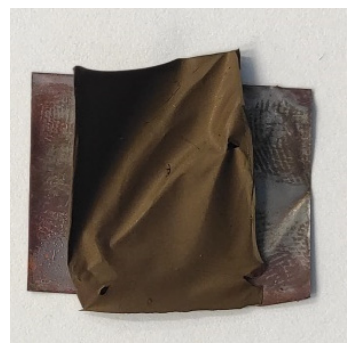

(f)

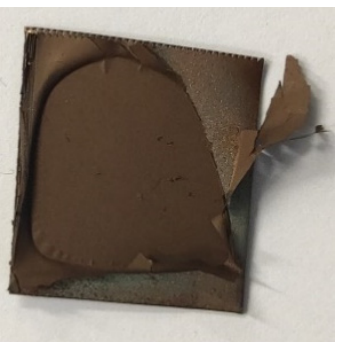

(i)

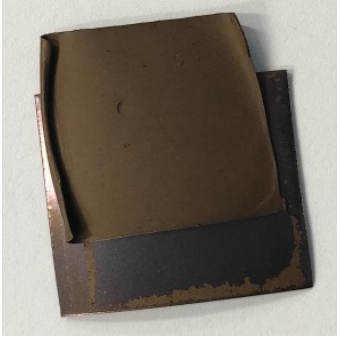

(c)

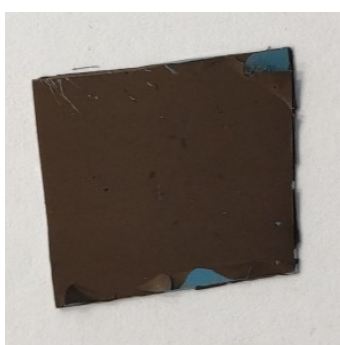

(g)

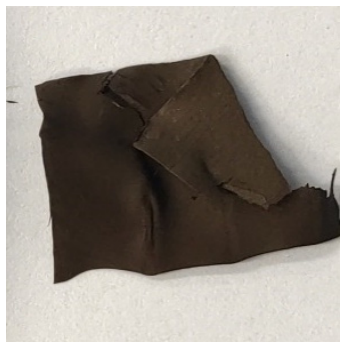

(j)

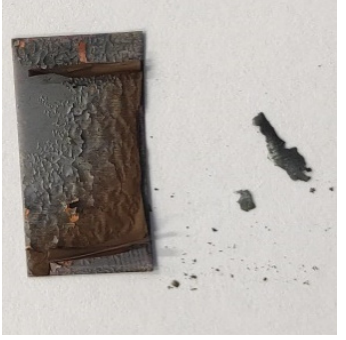

(d)

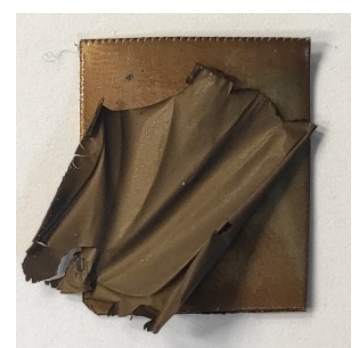

(h)

Figure 6. Nanofiber mats, incipiently carbonized at $500^{\circ} \mathrm{C}$ after stabilization for $1 \mathrm{~h}$ at $280^{\circ} \mathrm{C}$, approached by a heating rate of $0.25 \mathrm{~K} / \mathrm{min}$ : (a) aluminum; (b) copper foil tin-coated; (c) titanium sheet; (d) copper foil thick; (e) copper foil middle; (f) copper foil thin; (g) Si wafer; (h) stainless steel V2a; (i) steel st235jr; (j) pure PAN nanofiber mat.

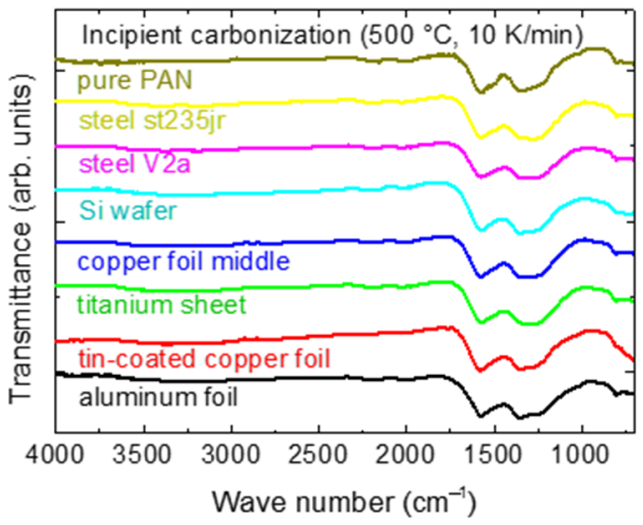

(a)

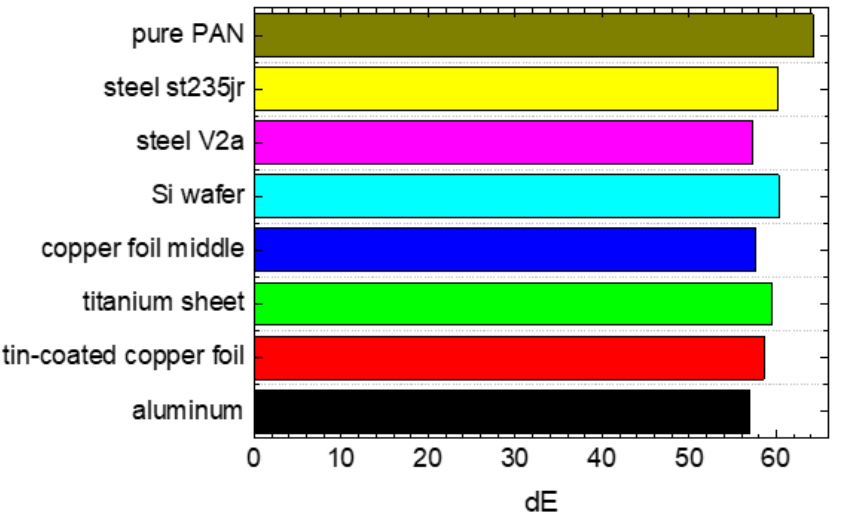

(b)

Figure 7. (a) FTIR measurements of nanofiber mats from Figure 6. Lines are vertically shifted for clarity. (b) Color differences $\mathrm{dE}$ of the samples from Figure 6. 
Similar to Figure $2 b$, the colors of the incipiently carbonized nanofiber mats with or without substrates are nearly identical, as depicted in Figure $7 \mathrm{~b}$. The slight differences can be assumed to be not significant; for a statistically relevant comparison, more or larger samples would be necessary to enable measuring on several samples or at diverse positions, respectively.

Since the $\mathrm{dE}$ values only show color differences to the white reference as scalars, it is not possible to distinguish between two dark colors using this number. Thus, Figure 8 depicts the measured spectra for samples after stabilization (cf. Figure 1) and after incipient carbonization (cf. Figure 6). For a fully black sample, the spectra could be expected to be approximately parallel to the x-axis, while colored samples should show maxima and/or minima. This is indeed visible in Figure 8. While the brownish stabilized samples show a clear remission maximum in the red range (Figure $8 \mathrm{a}$ ), the slopes of the curves are much flatter after incipient carbonization (Figure 8b), quantifying the difference in the color after stabilization and incipient carbonization.

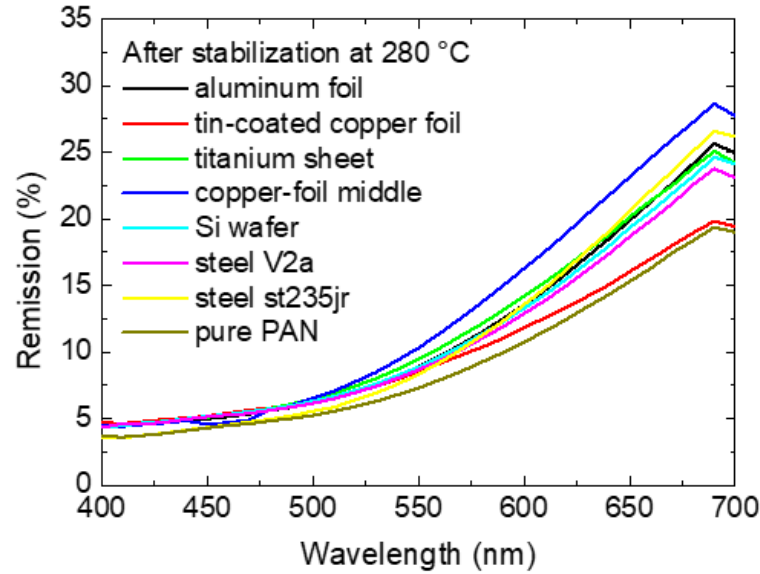

(a)

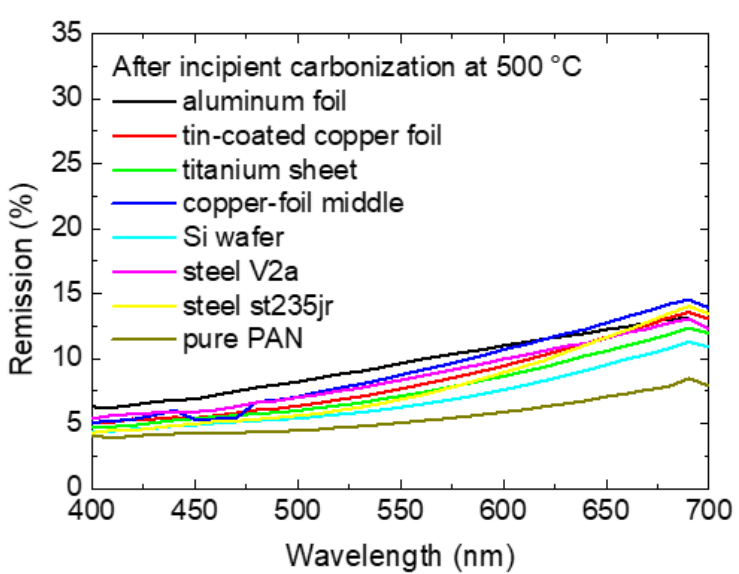

(b)

Figure 8. Remission spectra of (a) stabilized samples (cf. Figure 1); (b) incipiently carbonized samples (cf. Figure 6).

To investigate the influence of the substrate on the morphology of the incipiently carbonized nanofiber mats, Figure 9 depicts SEM images of samples carbonized at $500{ }^{\circ} \mathrm{C}$ without substrate or on thin copper foil.

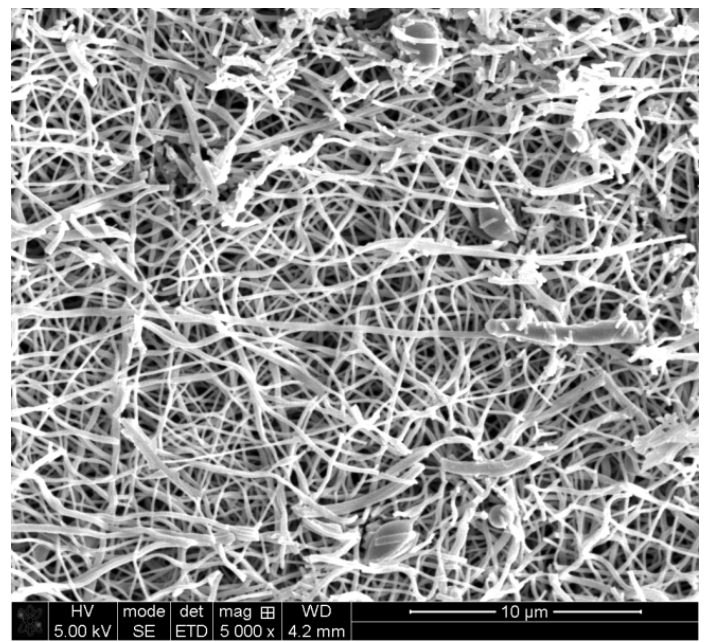

(a)

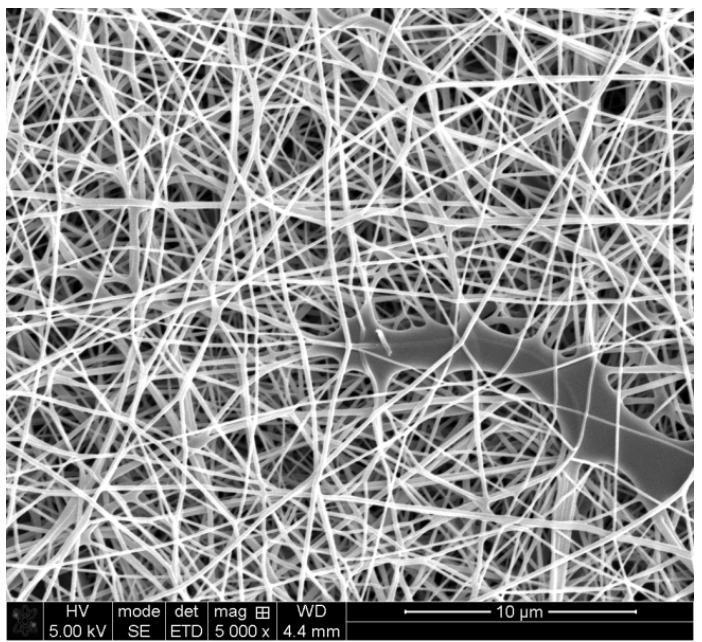

(b)

Figure 9. (a) Pure PAN nanofiber mat after carbonization at $500{ }^{\circ} \mathrm{C}$; (b) PAN nanofiber mat on thin copper foil after carbonization at $500{ }^{\circ} \mathrm{C}$. 
Here, opposite to the previous images after stabilization, clear differences are visible. While the nanofiber mat on the thin copper foil looks unchanged after incipient carbonization, the pure nanofiber mat (Figure 8a) shows several broken and conglutinated fibers, indicating that carbonization on a metal substrate is indeed supportive to maintain the desired morphology.

In analogy to Figure 4, Figure 10 shows the influence of the stabilization temperature on the carbonization process. The sample stabilized at $360{ }^{\circ} \mathrm{C}$ was not further used since there was no difference in the FTIR spectra of the samples stabilized at the highest temperatures. The other three samples (on tin-coated copper foil) do not show significant optical differences; color measurements did not reveal significant differences, either.

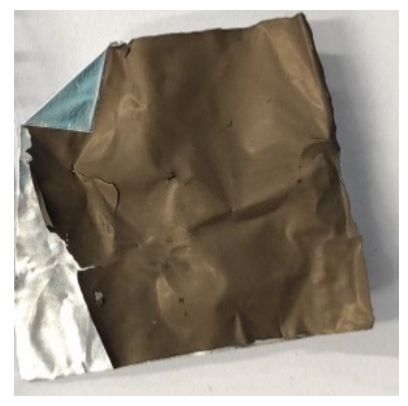

(a)

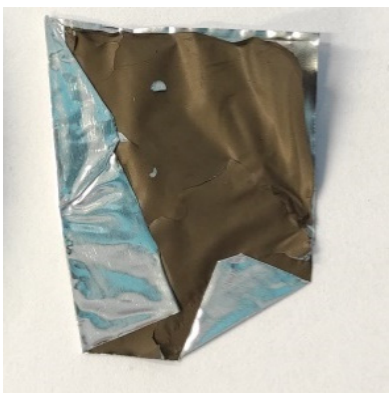

(b)

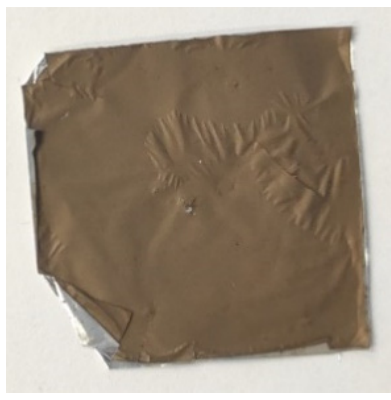

(c)

Figure 10. Nanofiber mats, carbonized for $1 \mathrm{~h}$ at $500{ }^{\circ} \mathrm{C}$, approached by a heating rate of $10 \mathrm{~K} / \mathrm{min}$, after stabilization on aluminum at (a) $200{ }^{\circ} \mathrm{C}$; (b) $240{ }^{\circ} \mathrm{C}$; (c) $320^{\circ} \mathrm{C}$.

To investigate the chemical properties, Figure 11 shows the FTIR graphs of these samples and the sample carbonized after stabilization at $280{ }^{\circ} \mathrm{C}$ (Figure $7 \mathrm{a}$ ). Comparing these graphs leads to an unexpected finding. As Figure 7a revealed, more pronounced $\mathrm{C}-\mathrm{O}$ vibrations in the wave number range of $1230-1250 \mathrm{~cm}^{-1}$ show beginning carbonization, as opposed to pure stabilization. Figure 11 clearly shows that this peak is more pronounced for incipient carbonization after stabilization at relatively low temperatures, while it is clearly reduced for incipient carbonization after stabilization at $320^{\circ} \mathrm{C}$.

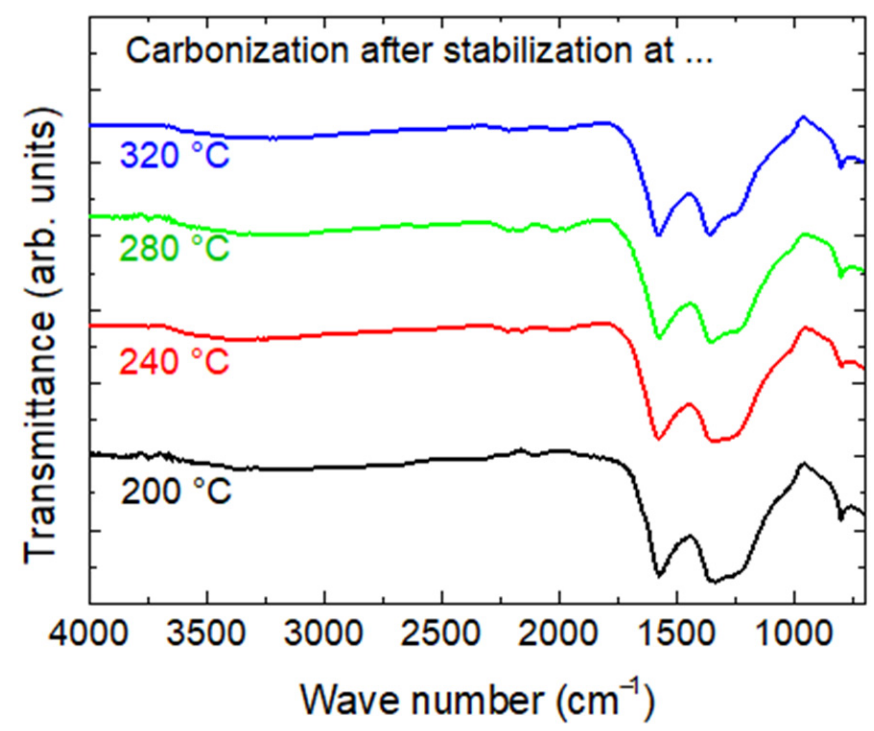

Figure 11. FTIR measurements of nanofiber mats, incipiently carbonized at $500{ }^{\circ} \mathrm{C}$ after stabilization on aluminum foil at different temperatures for $1 \mathrm{~h}$. Lines are vertically shifted for clarity. 
Combined with Figure 5, this finding suggests using a reduced stabilization temperature between 240 and $280{ }^{\circ} \mathrm{C}$ in combination with a heating rate of $0.25 \mathrm{~K} / \mathrm{min}$ to reach this temperature, to achieve optimum carbonization results. This will be investigated in more detail in the near future, with a finer temperature resolution and also on other substrates.

Next, the influence of the heating rate applied to reach the temperature of incipient carbonization was investigated. Figure 12 depicts photographic images of the samples carbonized with different heating rates between $1 \mathrm{~K} / \mathrm{min}$ and $50 \mathrm{~K} / \mathrm{min}$ (the maximum possible heating rate). Generally, the smaller heating rates seem to lead to a less brownish and more greyish color. This is, however, not displayed in the $\mathrm{dE}$ values which do not show significant differences. For a heating rate of $20 \mathrm{~K} / \mathrm{min}$ (Figure 12d), an unusually bright color is visible, which may be attributed to this nanofiber mat being attached nearly fully to the substrate after incipient carbonization, i.e., to the better retained morphology of the nanofiber mat, as discussed before.

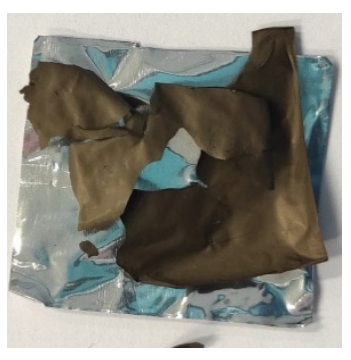

(a)

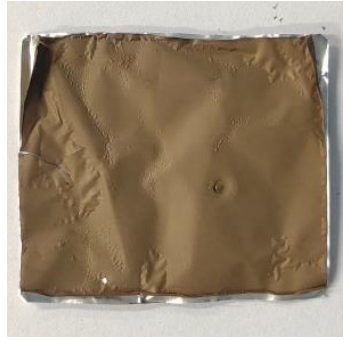

(d)

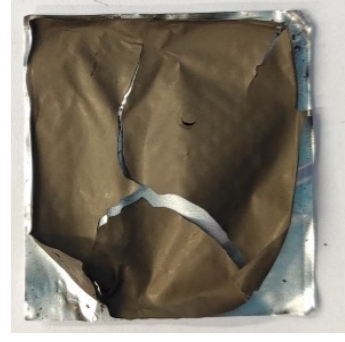

(b)

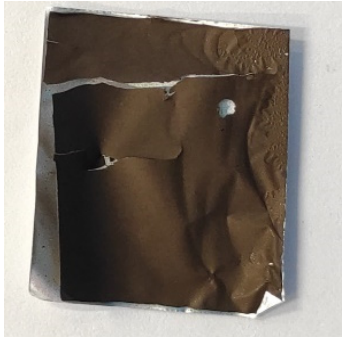

(e)

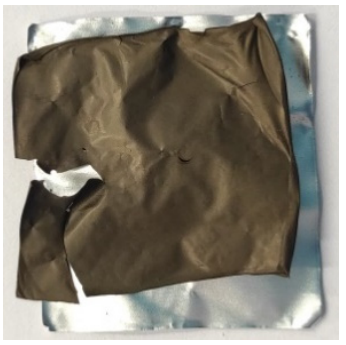

(c)

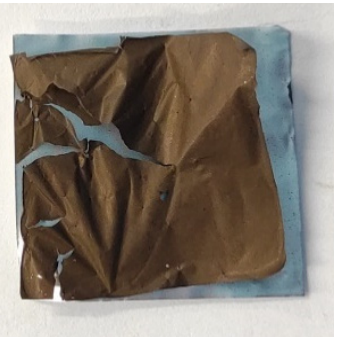

$(\mathbf{f})$

Figure 12. Nanofiber mats, incipiently carbonized after stabilization $\left(280{ }^{\circ} \mathrm{C}\right.$ for $1 \mathrm{~h}$, approached by $0.25 \mathrm{~K} / \mathrm{min}$ ) on aluminum for $1 \mathrm{~h}$ at $500{ }^{\circ} \mathrm{C}$, approached by a heating rate of (a) $1 \mathrm{~K} / \mathrm{min}$; (b) $2 \mathrm{~K} / \mathrm{min}$; (c) $5 \mathrm{~K} / \mathrm{min}$; (d) $20 \mathrm{~K} / \mathrm{min}$; (e) $40 \mathrm{~K} / \mathrm{min}$; (f) $50 \mathrm{~K} / \mathrm{min}$. A similar sample approached with the standard heating rate of $10 \mathrm{~K} / \mathrm{min}$ is depicted in Figure $6 \mathrm{a}$.

It must also be mentioned that some of the nanofiber mats are partly or even fully detached from the substrates after incipient carbonization. This finding must be investigated in detail in the future to establish a reliable process to either separate both parts or to form composites.

The chemical investigation of these samples by FTIR (Figure 13) indeed reveals small modifications of the peak near $1230-1250 \mathrm{~cm}^{-1}$, showing a trend to pronounced $\mathrm{C}-\mathrm{O}$ vibrations and thus possibly a slightly higher degree of carbonization for the samples with smaller heating rates. However, these findings cannot be quantified from the FTIR graphs and are thus not significant without further investigation.

The main aim of this study, however, was the investigation whether carbonization at high temperatures is enabled by leaving the nanofiber mats attached to a substrate. Previous experiments often revealed the problem that the fine nanofiber mats were moved away by the constant gas flow. On the other hand, many studies discuss the necessity of a relatively high gas flow to ensure full carbonization, i.e., to prevent contamination by air 
and to provide removal of emitted off-gas during carbonization [28]. Thus, fixation on a substrate may help solving this problem.

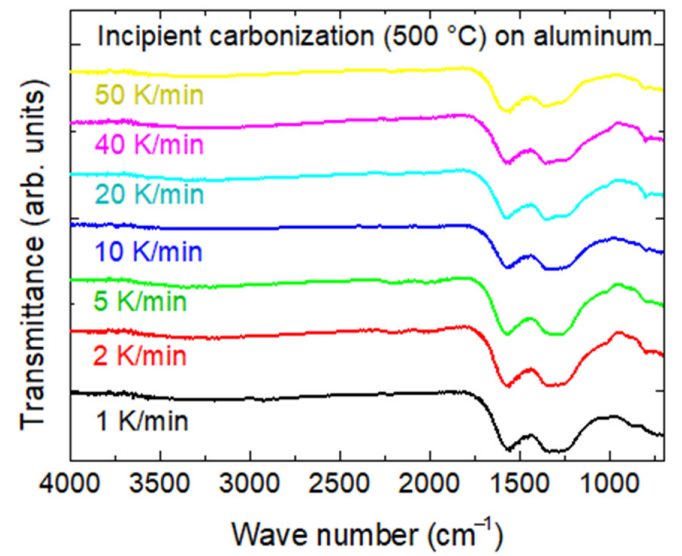

Figure 13. FTIR measurements of nanofiber mats on aluminum foil, incipiently carbonized at $500{ }^{\circ} \mathrm{C}$ with different heating rates after stabilization $\left(280^{\circ} \mathrm{C}\right.$ for $1 \mathrm{~h}$, approached with $\left.0.25 \mathrm{~K} / \mathrm{min}\right)$. Lines are vertically shifted for clarity.

Figure 14 shows carbonization results at higher temperatures on suitable substrates, i.e., copper foils. Carbonization on the Si wafer and on the titanium sheet led to a loss of the sample which was detached during the process.

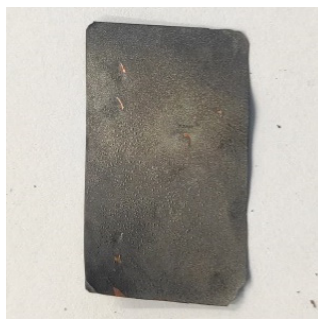

(a)

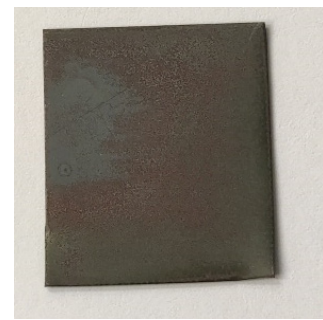

(b)

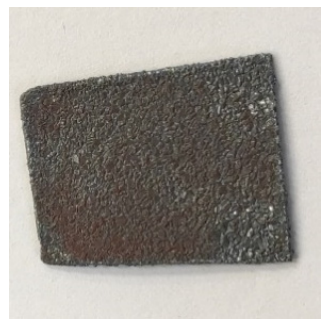

(c)

Figure 14. Nanofiber mats, carbonized after stabilization for $1 \mathrm{~h}$ at $280{ }^{\circ} \mathrm{C}$, approached by a heating rate of $0.25 \mathrm{~K} / \mathrm{min}$ : (a) copper foil thin $\left(900^{\circ} \mathrm{C}\right)$; (b) stainless steel V2a $\left(1200^{\circ} \mathrm{C}\right)$; (c) steel st235jr $\left(1200^{\circ} \mathrm{C}\right)$.

On the copper foils, there is still a slightly greyish color visible instead of the expected black tone. The FTIR measurements performed for the chemical evaluation revealed nearly no more peaks, as usual for carbon [25]. However, due to the problem to distinguish between vanishing peaks due to full carbonization or due to a lost nanofiber mat, these FTIR results are not taken into consideration here. Instead, microscopic images will be used next to evaluate this question.

The main aim of stabilizing and carbonizing PAN nanofiber mats on substrates is the possibility to unambiguously fix the sample dimensions during thermal treatment. This is especially important since most applications of carbon nanofibers or nanofiber mats, such as electrodes in pseudo- or supercapacitors, batteries or fuel cells [29-35], necessitate intact, strong fibers without undesired modifications of their morphology by shrinking, bending or even breaking.

To investigate this aspect, CLSM images are used, offering high enough resolution to evaluate the nanofibers without the danger to see too small areas only [35] and at the same time allowing seeing colors and thus obtaining an impression of the spatially resolved stabilization effort. 
Figure 15 gives an overview of the samples stabilized at $280{ }^{\circ} \mathrm{C}$ for $1 \mathrm{~h}$, approached by $0.25 \mathrm{~K} / \mathrm{min}$, on diverse substrates. Most of the samples look very similar, with similar colors and straight, long fibers. Only the pure nanofiber mat (Figure 15h) shows a darker color, as already recognized in Figure $1 \mathrm{~h}$, and thicker, more bent fibers, as expected. Besides, all samples show a certain inhomogeneity, as can be recognized by the color modification. Here, the nanofiber mat on the thick copper foil belongs to the apparently more homogeneous samples. It must be mentioned, however, that even with this relatively large field of view, only a small part of a sample is visible. Additional images (not shown here) revealed also inhomogeneous areas on this substrate.

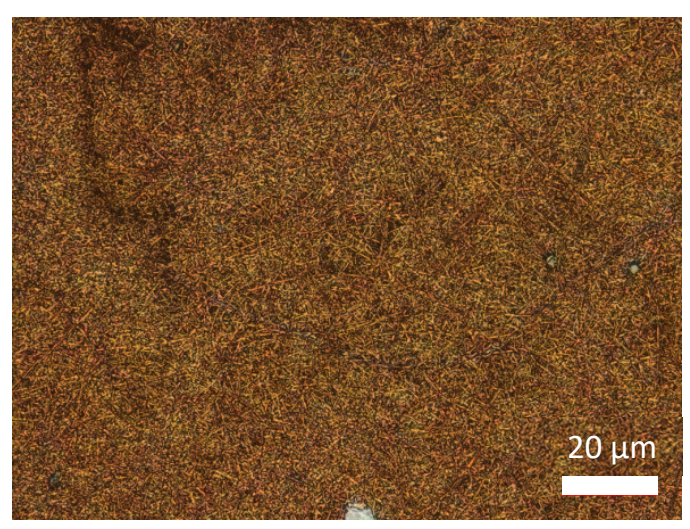

(a)

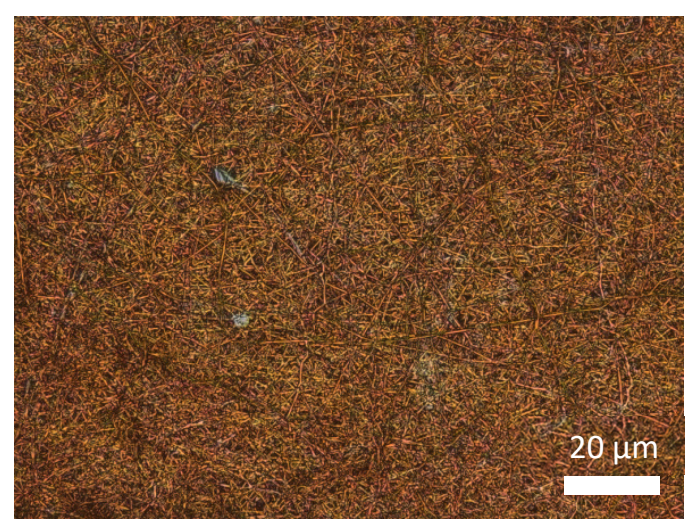

(c)

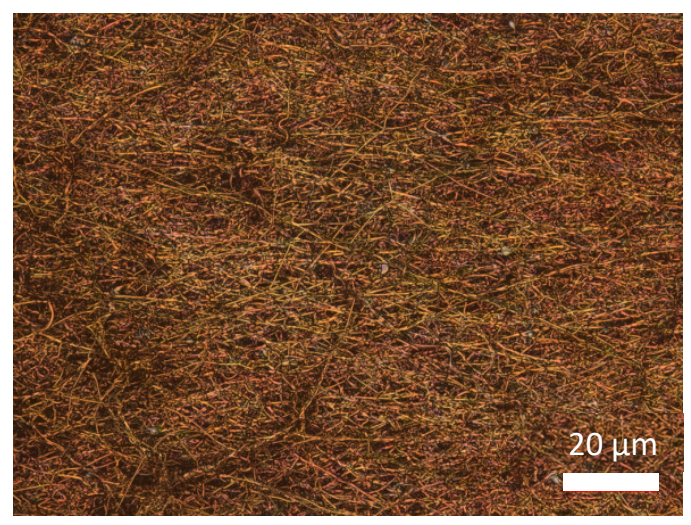

(e)

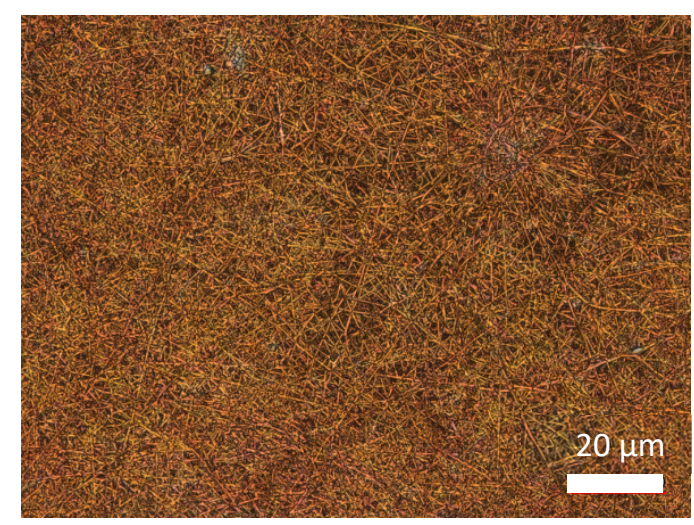

(b)

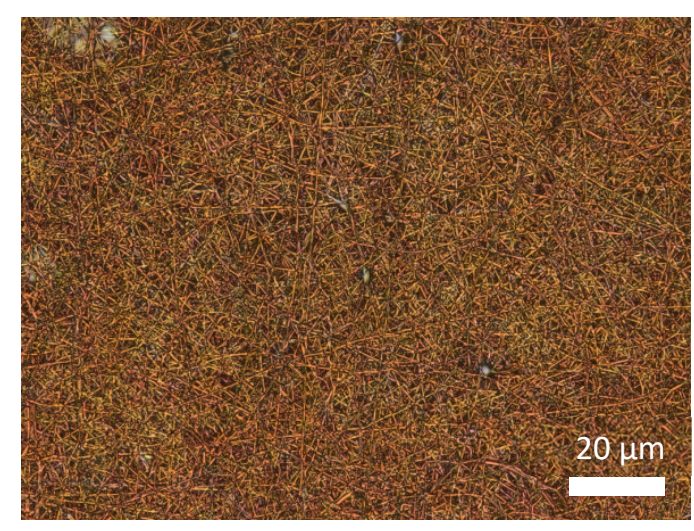

(d)

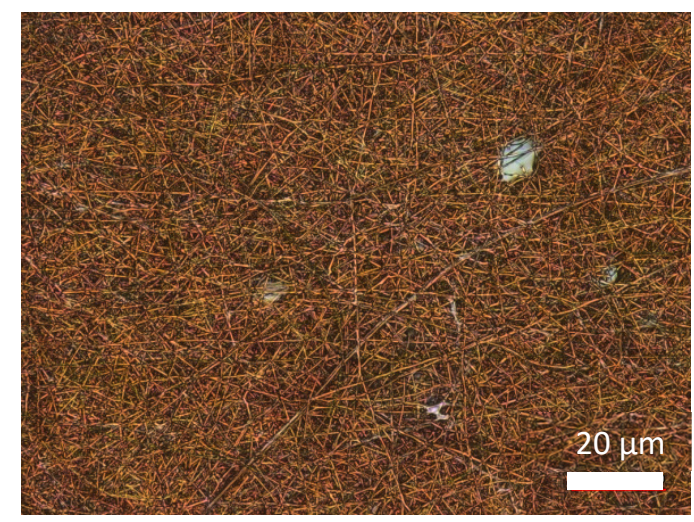

(f)

Figure 15. Cont. 


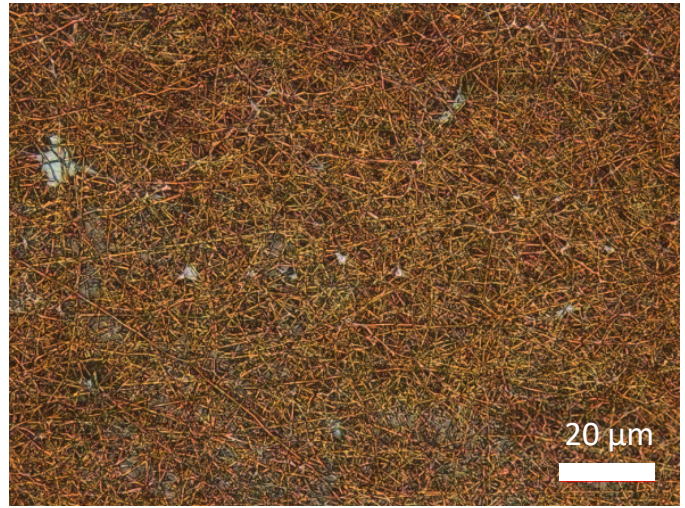

(g)

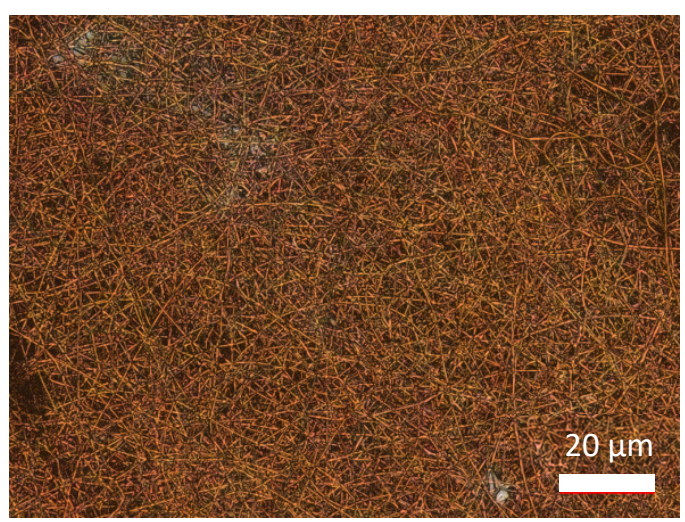

(i)

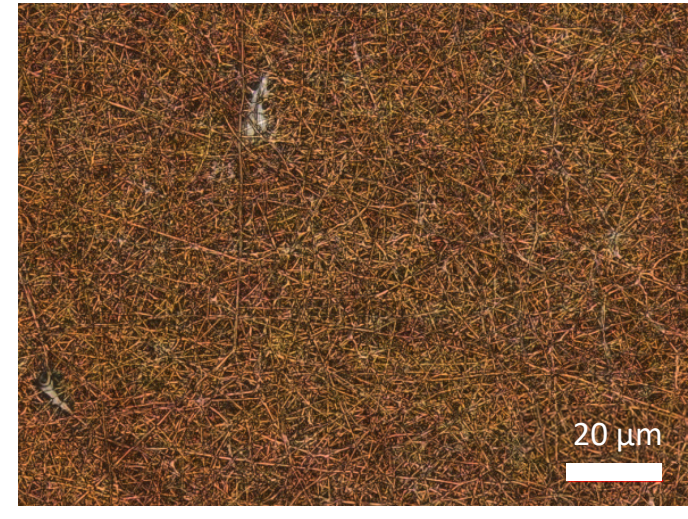

(h)

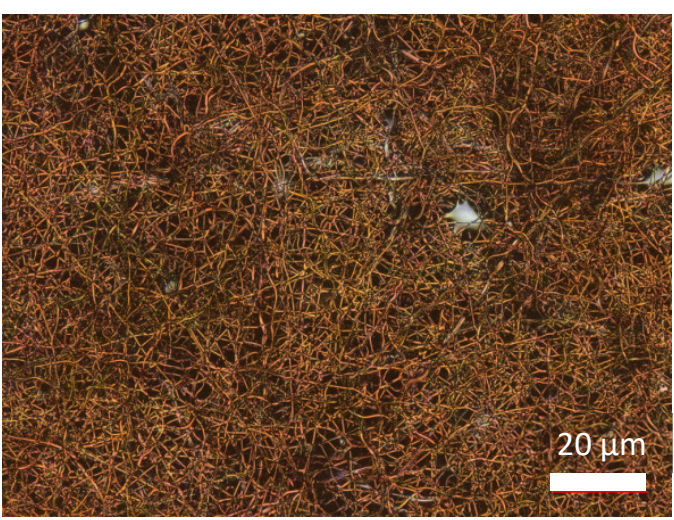

$(\mathbf{j})$

Figure 15. Confocal laser scanning microscopy (CLSM) images of nanofiber mats, stabilized for $1 \mathrm{~h}$ at $280{ }^{\circ} \mathrm{C}$, approached by a heating rate of $0.25 \mathrm{~K} / \mathrm{min}$ : (a) aluminum; (b) copper foil tin-coated; (c) titanium sheet; (d) copper foil thick; (e) copper foil middle; (f) copper foil thin; (g) Si wafer; (h) stainless steel V2a; (i) steel st235jr; (j) pure PAN nanofiber mat.

Next, Figure 16 shows the impact of the heating rate during stabilization, corresponding to the samples depicted in Figure 4.

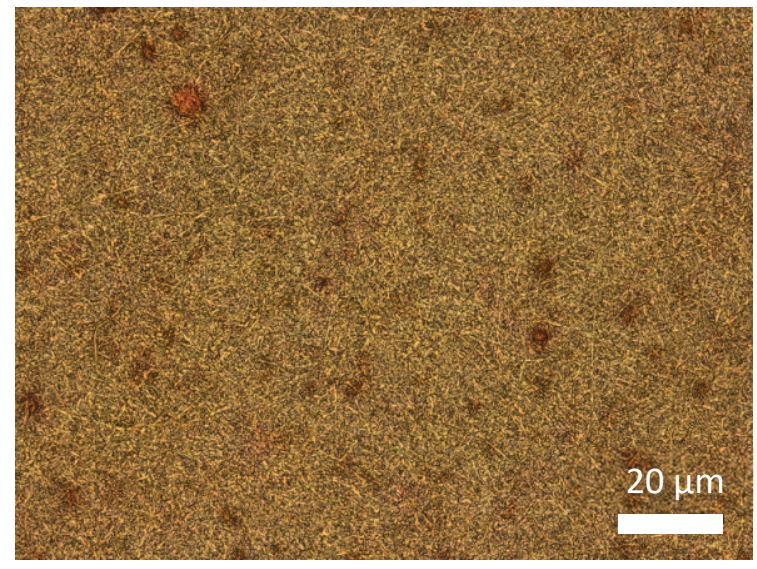

(a)

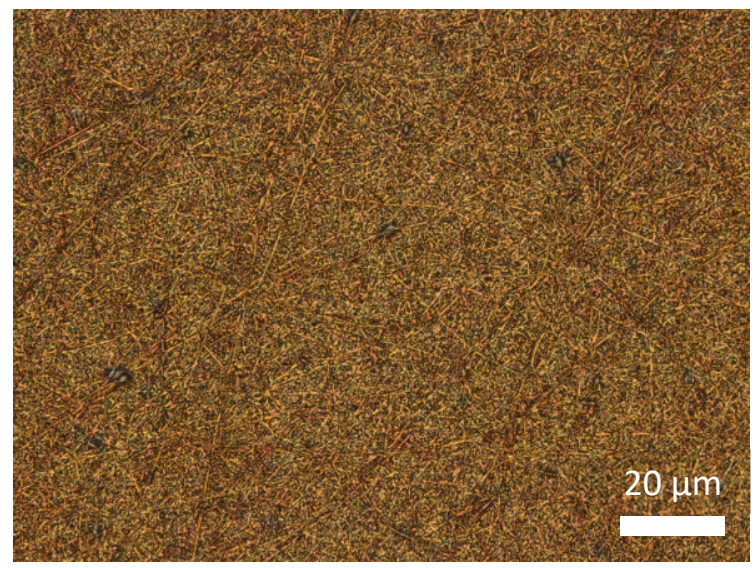

(b)

Figure 16. Cont. 


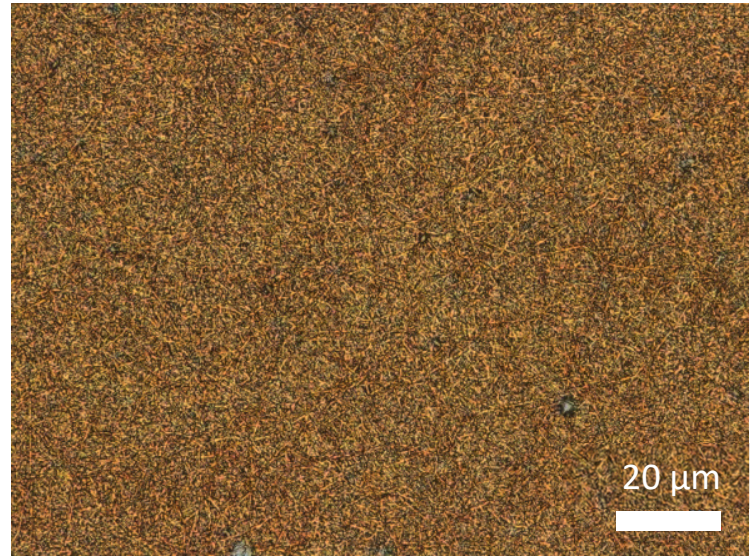

(c)

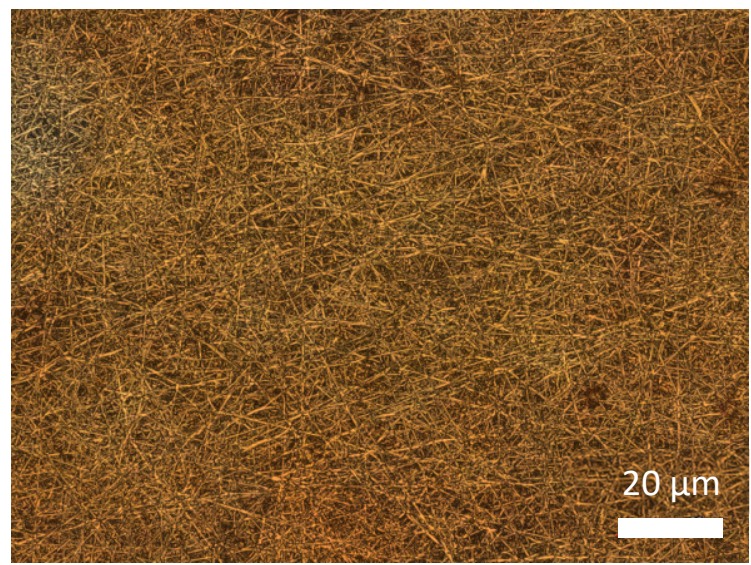

(e)

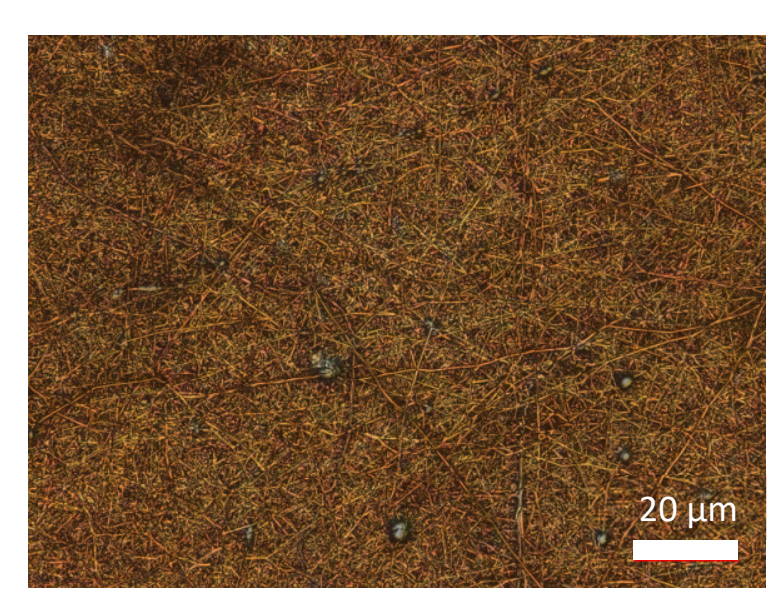

(g)

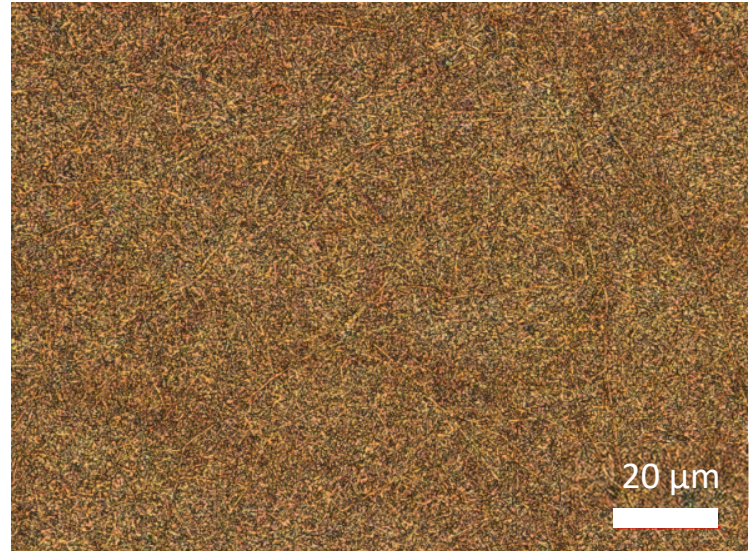

(d)

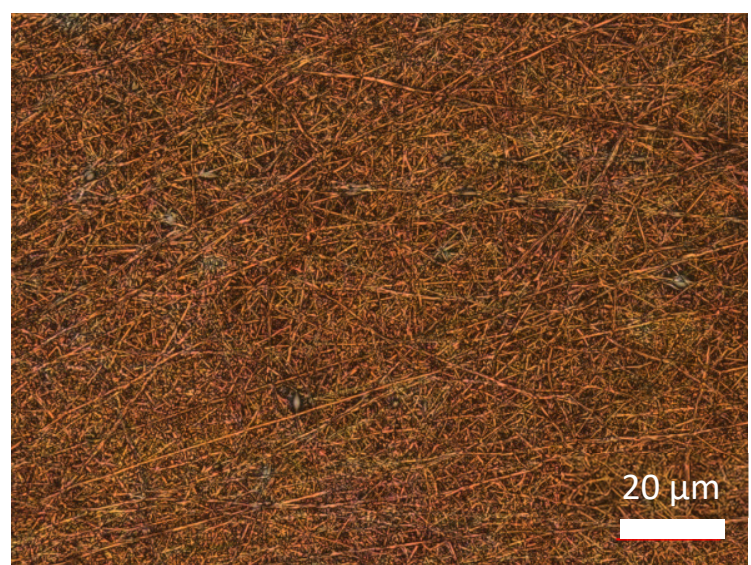

(f)

Figure 16. CLSM images of nanofiber mats, stabilized for $1 \mathrm{~h}$ at different temperatures, approached by a heating rate of $0.25 \mathrm{~K} / \mathrm{min}$, on (a) aluminum at $200{ }^{\circ} \mathrm{C}$; (b) $240{ }^{\circ} \mathrm{C}$; (c) $320{ }^{\circ} \mathrm{C}$; (d) $360{ }^{\circ} \mathrm{C}$; (e) copper foil tin-coated at $200{ }^{\circ} \mathrm{C}$; (f) $240{ }^{\circ} \mathrm{C}$; (g) $320^{\circ} \mathrm{C}$.

While the macroscopic images of the samples in Figure 4 revealed only slight color differences between both substrates, here these deviations become more pronounced. 
Especially for stabilization on the aluminum substrate at $200{ }^{\circ} \mathrm{C}$, there are small darker spots in a generally light brown nanofiber mat, indicating probably full stabilization only at these spots. Even for $240^{\circ} \mathrm{C}$, there are still color variations visible, leading to the conclusion that a temperature of $240{ }^{\circ} \mathrm{C}$ may be slightly too low for full stabilization, and $250{ }^{\circ} \mathrm{C}$, e.g., should be tested instead.

On the tin-coated copper foil, however, the colors are clearly darker for all temperatures, and no irregularities are visible for the lower temperatures.

This indicates that a more detailed study of stabilization temperatures on all substrates should be carried out, possibly resulting in the finding that this process can be carried out with less energy consumption if an optimum substrate is chosen.

Next, the samples after incipient carbonization at $500{ }^{\circ} \mathrm{C}$ are presented in Figure 18, analogously to Figure 6 . On the one hand, all samples still show a brownish color, underlining that carbonization has only slightly started at this temperature, but is far from being completed. The pure nanofiber mat again shows the darkest color and correspondingly relatively thick, bent nanofibers. Especially on aluminum, the color is less brownish, suggesting that here possibly carbonization has proceeded further. However, these differences are not significant and cannot be used to rate some of these substrates as especially well-suited as substrates for stabilization and carbonization.

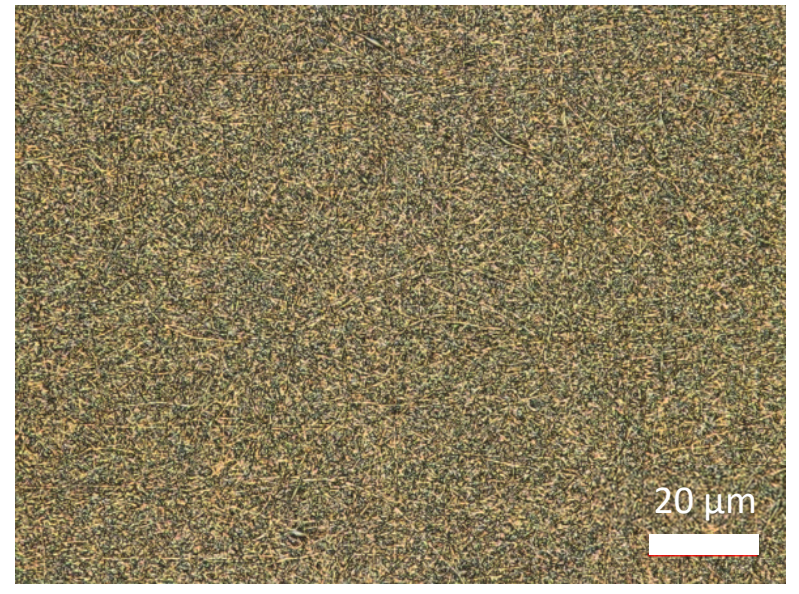

(a)

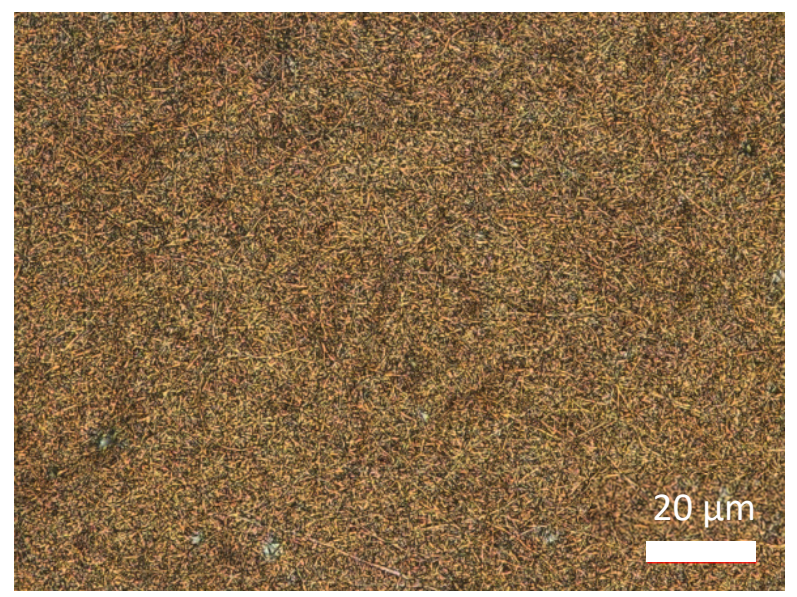

(c)

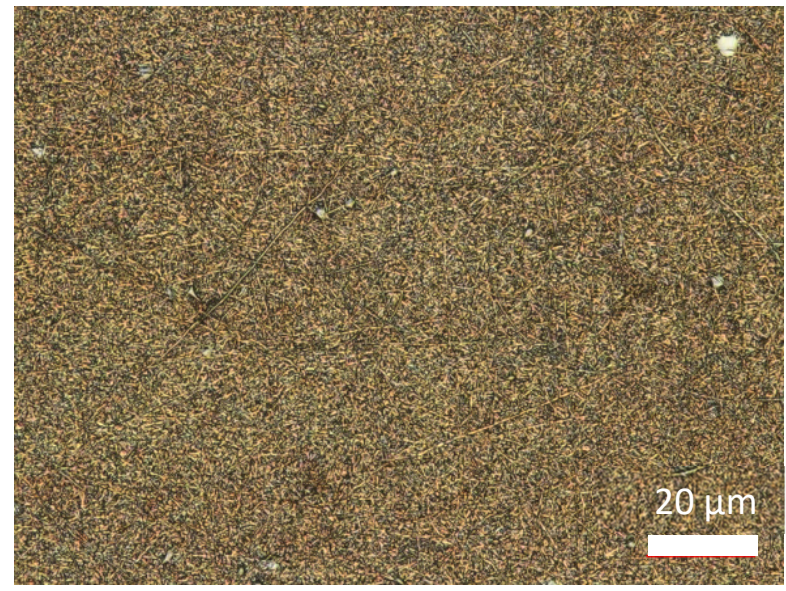

(b)

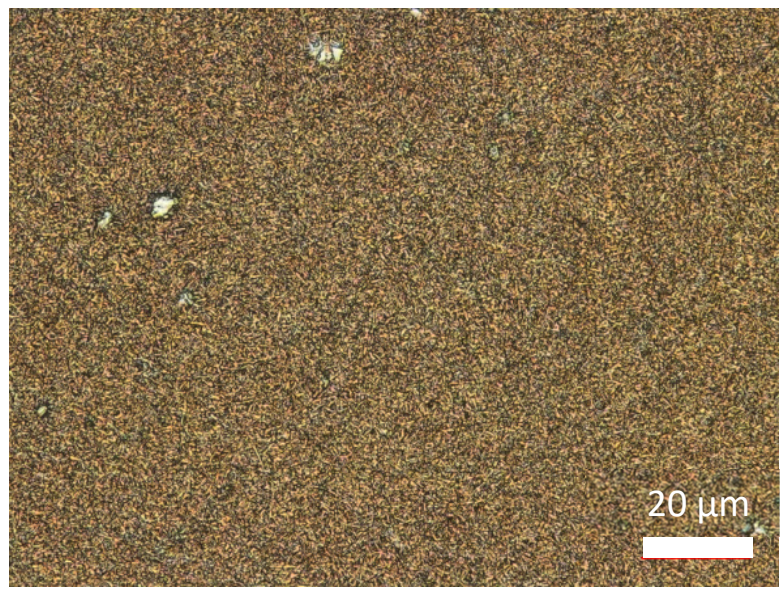

(d)

Figure 17. Cont. 


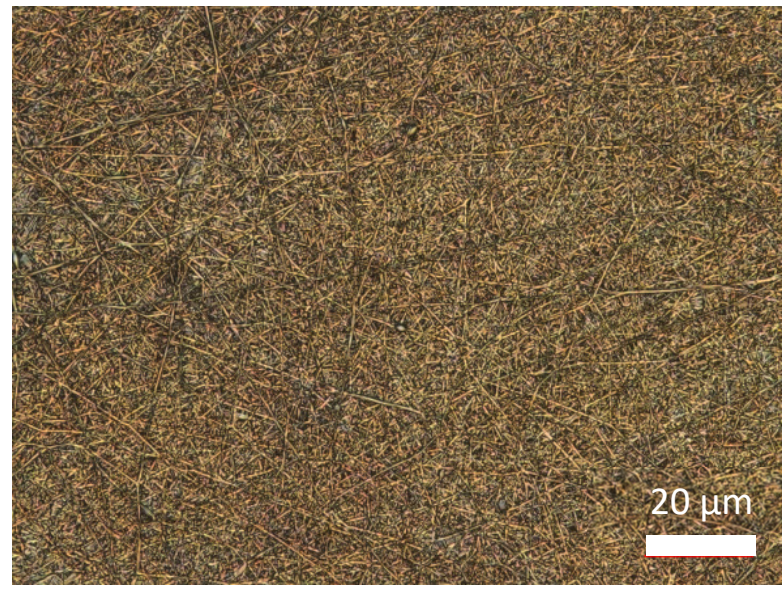

(e)

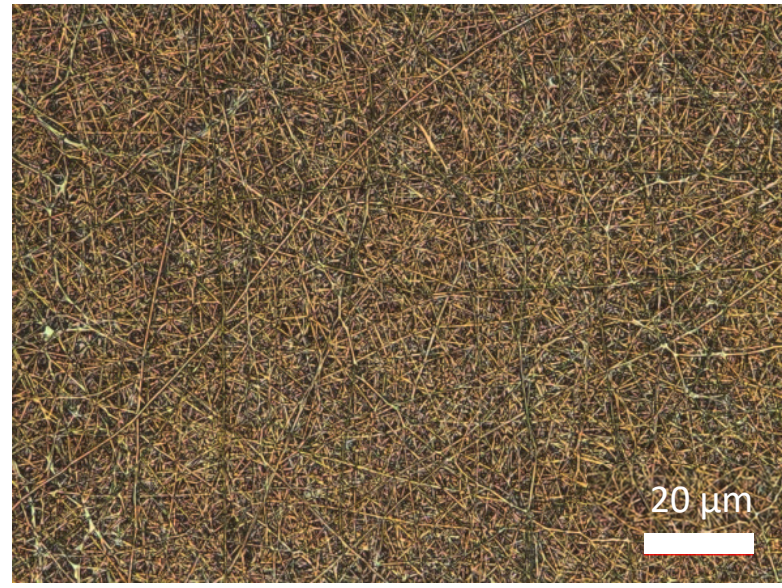

(g)

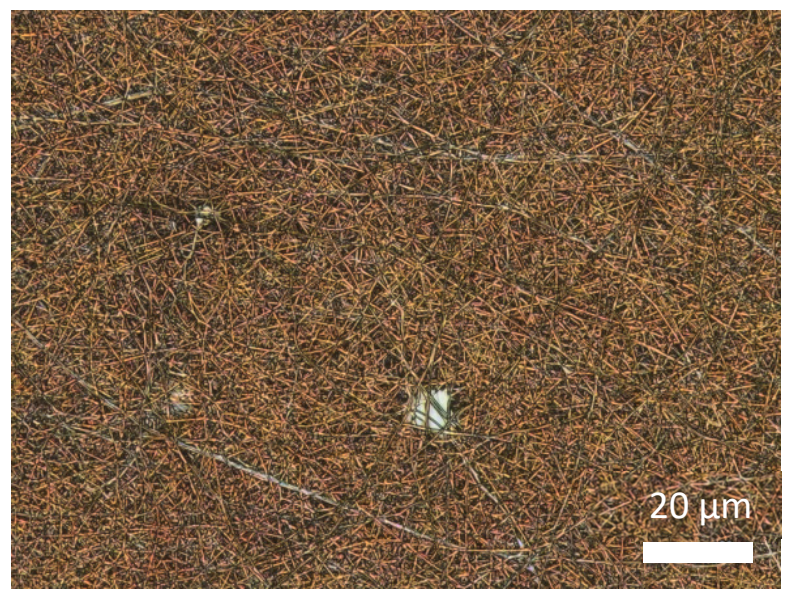

(i)

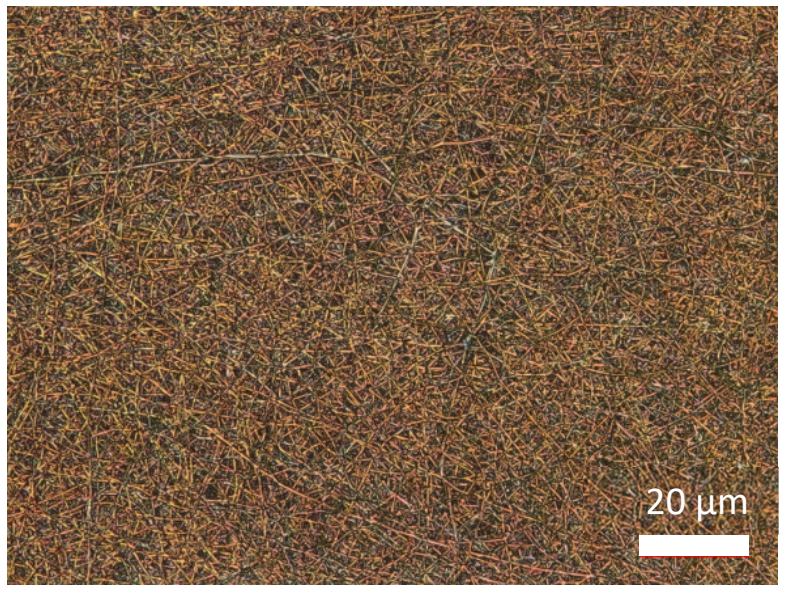

(f)

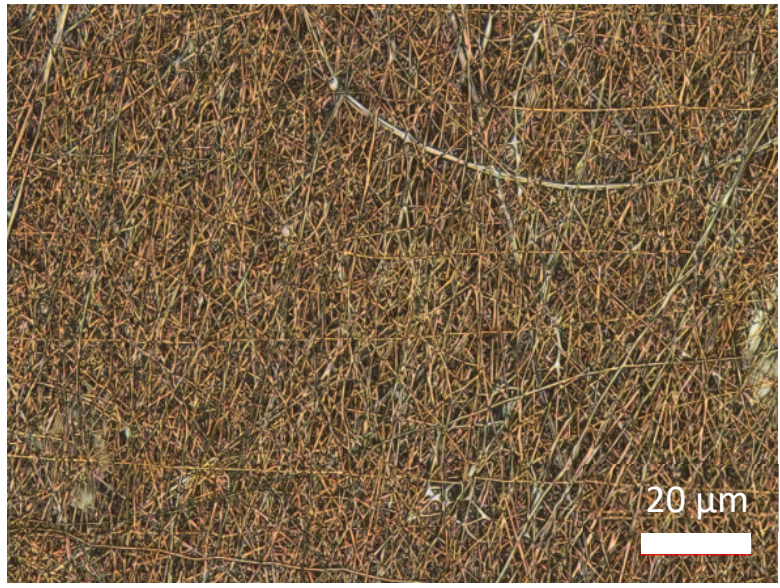

(h)

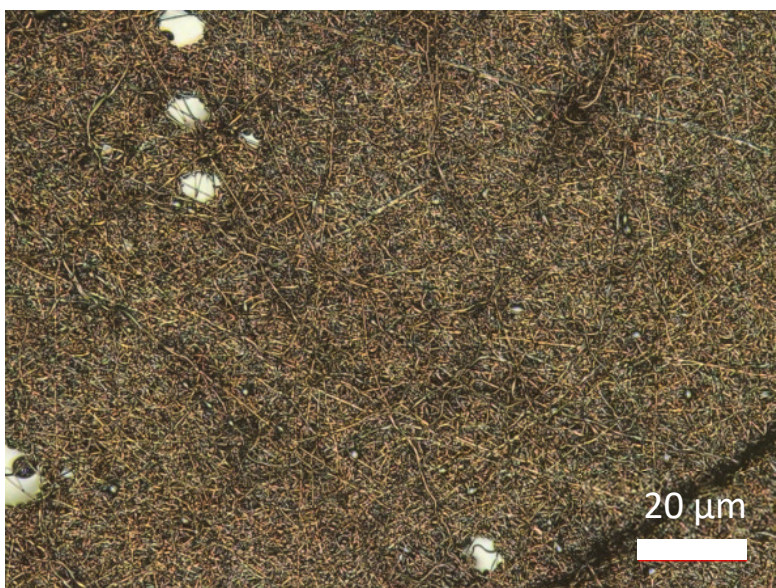

(j)

Figure 18. Nanofiber mats, carbonized at $500{ }^{\circ} \mathrm{C}$ after stabilization for $1 \mathrm{~h}$ at $280{ }^{\circ} \mathrm{C}$, approached by a heating rate of $0.25 \mathrm{~K} / \mathrm{min}$ : (a) aluminum; (b) copper foil tin-coated; (c) titanium sheet; (d) copper foil thick; (e) copper foil middle; (f) copper foil thin; (g) Si wafer; (h) stainless steel V2a; (i) steel st235jr; (j) pure PAN nanofiber mat. 
To evaluate the influence of the stabilization temperature on subsequent carbonization (cf. Figures 6 and 7a) more in detail, Figure 19 shows CLSM images on the aluminum substrate, carbonized after stabilization at different temperatures. While the macroscopic images (Figure 6) revealed no significant color differences, here a clear color difference between the carbonized samples stabilized at low temperatures and at $320^{\circ} \mathrm{C}$ is visible, indicating that the latter is still more stabilized, while the others are already less brownish and thus slightly more carbonized. This finding is supported by the corresponding FTIR graphs (Figure 7a) which already indicated more pronounced $\mathrm{C}-\mathrm{O}$ vibrations, i.e., beginning carbonization for the samples stabilized at lower temperatures.

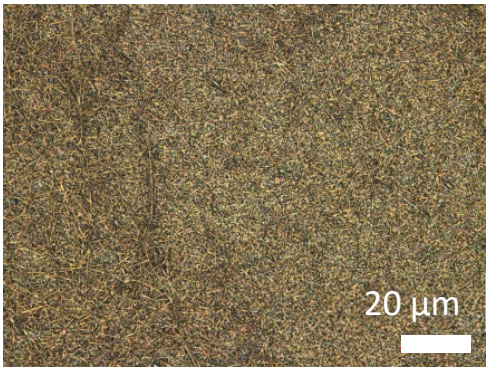

(a)

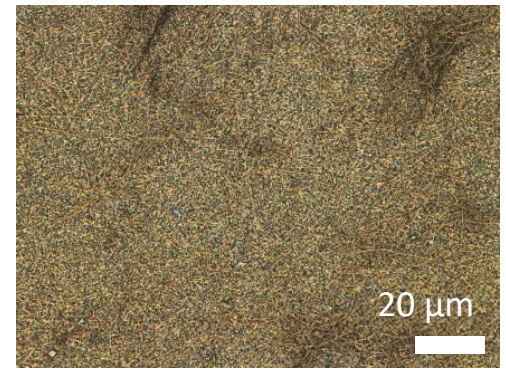

(b)

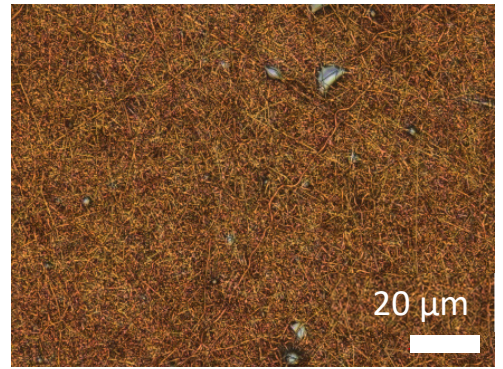

(c)

Figure 19. CLSM images of nanofiber mats, carbonized for $1 \mathrm{~h}$ at $500{ }^{\circ} \mathrm{C}$, approached by a heating rate of $10 \mathrm{~K} / \mathrm{min}$, after stabilization on aluminum at (a) $200{ }^{\circ} \mathrm{C}$; (b) $240{ }^{\circ} \mathrm{C}$; (c) $320^{\circ} \mathrm{C}$.

CLSM images of nanofiber mats incipiently carbonized at a temperature of $500{ }^{\circ} \mathrm{C}$, approached by different heating rates, are depicted in Figure 20. As already assumed according to Figures 12 and 13 , the heating rates below $10 \mathrm{~K} / \mathrm{min}$ result in slightly less brownish, i.e., more carbonized, nanofiber mats. Nevertheless, many more investigations, including color measurements, are necessary to evaluate whether these differences are quantitative.

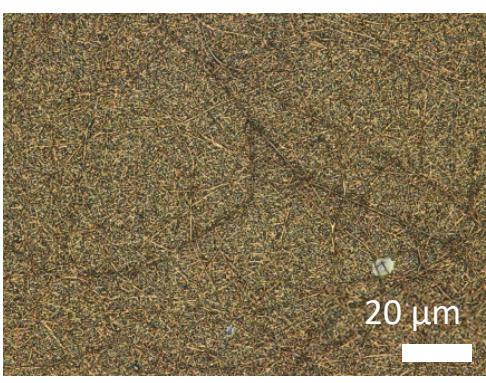

(a)

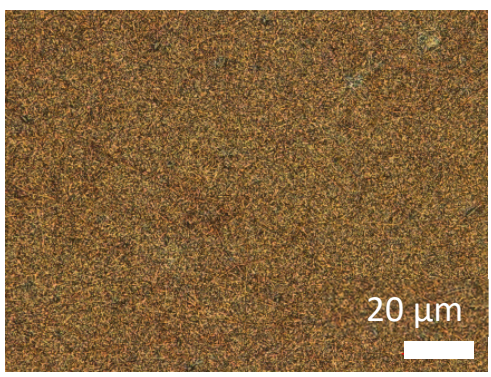

(d)

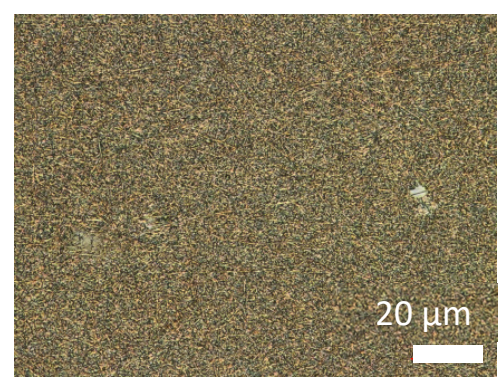

(b)

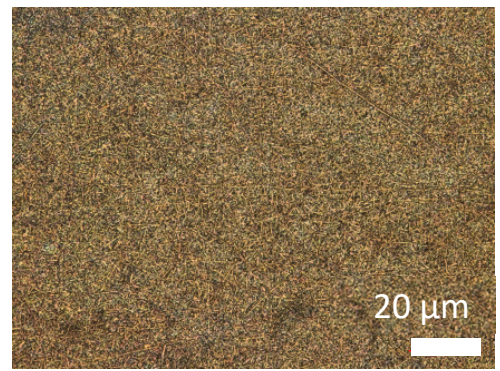

(e)

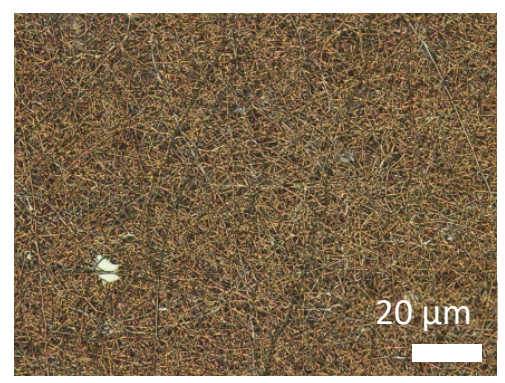

(c)

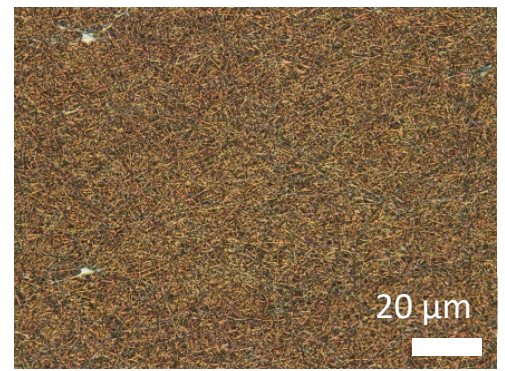

(f)

Figure 20. CLSM images of nanofiber mats, incipiently carbonized on aluminum for $1 \mathrm{~h}$ at $500{ }^{\circ} \mathrm{C}$, approached by a heating rate of (a) $2 \mathrm{~K} / \mathrm{min}$; (b) $5 \mathrm{~K} / \mathrm{min}$; (c) $10 \mathrm{~K} / \mathrm{min}$; (d) $20 \mathrm{~K} / \mathrm{min}$; (e) $40 \mathrm{~K} / \mathrm{min}$; (f) $50 \mathrm{~K} / \mathrm{min}$. 
Finally, Figure 21a shows a CLSM image of the sample carbonized on thin copper foil at $900{ }^{\circ} \mathrm{C}$. Here, we clearly see that both materials form a metal/carbon composite, in which the carbon nanofiber mat started sinking into the slightly molten copper. Brighter areas show a stronger reflection-as usual for metals-indicating that here, the copper is at the surface. Residual brown-orange colors are typical for incomplete carbonization, showing residues of stabilized PAN.

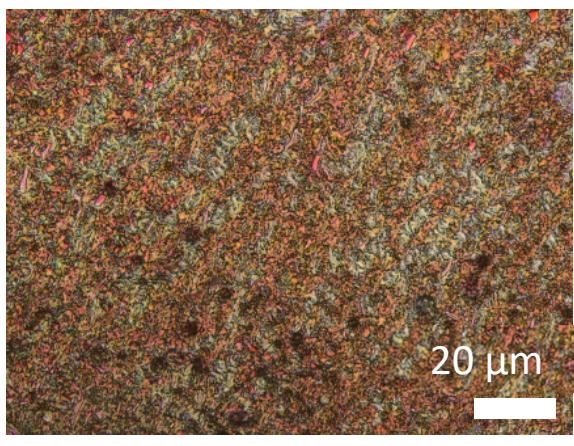

(a)

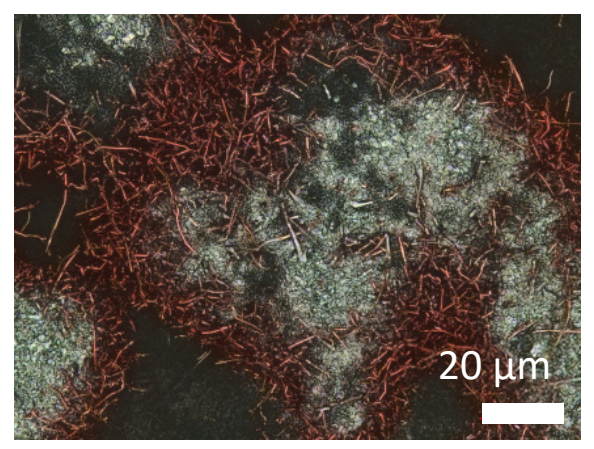

(b)

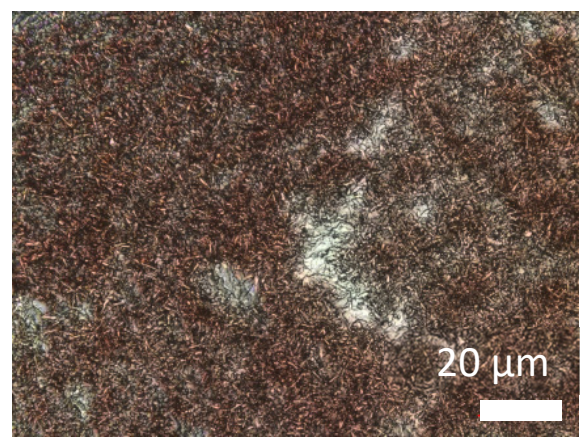

(c)

Figure 21. CLSM images of nanofiber mats, carbonized at high temperatures after stabilization for $1 \mathrm{~h}$ at $280^{\circ} \mathrm{C}$, approached by a heating rate of $0.25 \mathrm{~K} / \mathrm{min}$, on (a) thin copper foil $\left(900^{\circ} \mathrm{C}\right)$; (b) steel V2a $\left(1200^{\circ} \mathrm{C}\right)$; (c) steel st235jr $\left(1200{ }^{\circ} \mathrm{C}\right)$.

On both steel sheets, the nanofiber mats are also partly vanished or sunk into the metal surface (cf. Figure 19b,c). Especially on the V2a steel, the residues of the nanofiber mats look dark red, indicating a possible chemical modification in comparison with the nanofiber mat carbonized on copper at $900^{\circ} \mathrm{C}$. On the steel st235jr, the nanofiber mat looks slightly less reddish, but still quite different from the color of the sample carbonized on copper. These differences have to be investigated by FTIR to evaluate whether there are indeed chemical differences between the different carbon nanofiber mats.

It must be mentioned that these findings are not fully reproducible. On the other copper fabrics, e.g., no residual nanofiber mats were found. Thus, the procedure of preparing nano-composites has to be improved in the future, to prepare such nano-composites in a reliable way. Besides, SEM images of these samples revealed only few fibers along the surface. Future investigations at different carbonization temperatures are necessary to find out whether the missing carbon nanofiber mats vanish due to the nitrogen flow in the carbonization oven after being detached from the substrates, or whether they are fully integrated into the metal surface so that their shapes are nearly vanished, and only the larger-scale CLSM images are still able to find colored nanofiber residues.

Apparently, in this way it is indeed possible to prepare metal/carbon composites with a copper foil, as tested before with aluminum as substrate [26]. The mechanical properties of such composites will be tested in the near future.

\section{Conclusions and Outlook}

To conclude, PAN nanofiber mats were stabilized and carbonized at different temperatures on diverse substrates. All substrates could be used for the mechanical fixation of the nanofiber mats during stabilization; samples stabilized on substrates generally showed fine, straight fibers afterwards, as opposed to the thicker, bent fibers in the purely stabilized sample. Comparing photographs, FTIR graphs and CLSM images, it can be concluded that the optimum temperature for stabilization on a substrate, approached with a heating rate of $0.25 \mathrm{~K} / \mathrm{min}$, is slightly above $240{ }^{\circ} \mathrm{C}$.

Incipient carbonization is not only influenced by the stabilization temperature, but also to a certain amount by the substrate; however, this factor is less important. Carbonization at high temperatures, here, 900 or $1200{ }^{\circ} \mathrm{C}$, depending on the substrate, resulted in the 
preparation of metal/carbon composites whose mechanical properties will be investigated in the future.

Generally, the problem of sample parts or complete samples vanishing due to the steady gas flow in the furnace could not be reliably solved by carbonization on a substrate. Further tests will thus investigate the influence of sandwiching the samples during carbonization between two metal sheets or other substrates.

Author Contributions: Conceptualization, J.L.S. and T.G.; methodology, J.L.S. and T.G.; validation, J.L.S., T.G. and A.E.; formal analysis, A.E.; investigation, B.B., J.L.S., T.G., L.S., B.K., K.T., L.B., E.T.; resources, A.H.; supervision, A.H.; writing—original draft preparation, A.E.; writing—review and editing, all authors; visualization, T.G. and A.E. All authors have read and agreed to the published version of the manuscript.

Funding: This research was funded by the German Federal Ministry for Economic Affairs and Energy, grant number 03THW09K08.

Institutional Review Board Statement: Not applicable.

Informed Consent Statement: Not applicable.

Data Availability Statement: The data created in this study are contained within the article.

Acknowledgments: The authors would like to thank the company CMC Klebetechnik GmbH for providing samples of the tin-coated copper foil. Furthermore, the authors thank Alexander Depping for his kind support.

Conflicts of Interest: The authors declare no conflict of interest. The funders had no role in the design of the study; in the collection, analyses, or interpretation of data; in the writing of the manuscript, or in the decision to publish the results.

\section{References}

1. Greiner, A.; Wendor, J.H. Electrospinning: A fascinating method for the preparation of ultrathin fibers. Angew. Chem. Int. Ed. 2007, 46, 5670-5703. [CrossRef] [PubMed]

2. Rahaman, M.S.A.; Ismail, A.F.; Mustafa, A. A review of heat treatment on polyacrylonitrile fiber. Polym. Degrad. Stab. 2007, 92, 1421-1432. [CrossRef]

3. Sabantina, L.; Klöcker, M.; Wortmann, M.; Rodríguez-Mirasol, J.; Cordero, T.; Moritzer, E.; Finsterbusch, K.; Ehrmann, A. Stabilization of PAN nanofiber mats obtained by needleless electrospinning using DMSO as solvent. J. Ind. Text. 2020, 50, 224-239. [CrossRef]

4. Abdullah, N.; Othman, F.E.C.; Yusof, N.; Matsuura, T.; Lau, W.J.; Jaafar, J.; Ismail, A.F.; Salleh, W.N.W.; Aziz, F. Preparation of nanocomposite activated carbon nanofiber/manganese oxide and its adsorptive performance toward leads (II) from aqueous solution. J. Water Process. Eng. 2020, 37, 101430. [CrossRef]

5. Wang, J.; Park, Y.K.; Jo, Y.M. Sequential improvement of activated carbon fiber properties for enhanced removal efficiency of indoor $\mathrm{CO}_{2}$. J. Ind. Eng. Chem. 2020, 89, 400-408. [CrossRef]

6. Yang, Y.; Liu, Y.X.; Li, Y.; Deng, B.W.; Yin, B.; Yang, M.B. Design of compressible and elastic N-doped porous carbon nanofiber aerogels as binder-free supercapacitor electrodes. J. Mater. Chem. A 2020, 8, 17257-17265. [CrossRef]

7. Cheng, H.; Zhou, Z.Y.; Liu, T. Electro-spinning fabrication of nitrogen, phosphorus co-doped porous carbon nanofiber as an electro-chemiluminescent sensor for the determination of cyproheptadine. RSC Adv. 2020, 10, 23091-23096. [CrossRef]

8. Fokin, N.; Grothe, T.; Mamun, A.; Trabelsi, M.; Klöcker, M.; Sabantina, L.; Döpke, C.; Blachowicz, T.; Hütten, A.; Ehrmann, A. Magnetic properties of electrospun magnetic nanofiber mats after stabilization and carbonization. Materials 2020, 13, 1552. [CrossRef]

9. Xu, B.; Wang, X.B.; Huang, Y.Y. Electrospinning preparation of $\mathrm{PAN} / \mathrm{TiO}_{2} / \mathrm{PANI}$ hybrid fiber membrane with highly selective adsorption and photocatalytic regeneration properties. Chem. Eng. J. 2020, 399, 125749. [CrossRef]

10. Seong, M.; Kim, H.; Kim, C.; Lim, H.S.; Yoon, D.K.; Kim, T.H.; Ahn, H.J. Fabrication and electrochemical characterization of sulfurized-polyacrylonitrile nanofiber electrodes for $\mathrm{Na} / \mathrm{S}$ batteries using various polyacrylonitrile solutions. J. Nanosci. Nanotechnol. 2020, 20, 7092-7095. [CrossRef]

11. Ji, S.M.; Tiwari, J.P.; Kim, H.Y. PAN-ZnO//PAN-Mn ${ }_{3} \mathrm{O}_{4} / \mathrm{CeO}_{2}$ Janus nanofibers: Controlled fabrication and enhanced photocatalytic properties under UV and visible light. Chem. Phys. Lett. 2020, 759, 138050. [CrossRef]

12. Trabelsi, M.; Mamun, A.; Klöcker, M.; Sabantina, L.; Großerhode, C.; Blachowicz, T.; Ehrmann, A. Increased mechanical properties of carbon nanofiber mats for possible medical applications. Fibers 2019, 7, 98. [CrossRef]

13. Grothe, T.; Storck, J.L.; Dotter, M.; Ehrmann, A. Impact of solid content in the electrospinning solution on physical and chemical properties of polyacrylonitrile (PAN) nanofibrous mats. Tekstilec 2020, 63, 225-232. 
14. Bashir, Z. A critical review of the stabilisation of polyacrylonitrile. Carbon 1991, 29, 1081-1090. [CrossRef]

15. Ismar, E.; Sezai Sarac, A. Oxidation of polyacrylonitrile nanofiber webs as a precursor for carbon nanofiber: Aligned and non-aligned nanofibers. Polym. Bull. 2017, 75, 485-499. [CrossRef]

16. Fitzer, E.; Frohs, W.; Heine, M. Optimization of stabilization and carbonization treatment of PAN fibres and structural characterization of the resulting carbon fibres. Carbon 1986, 24, 387-395. [CrossRef]

17. Mathur, R.; Bahl, O.; Mittal, J. A new approach to thermal stabilization of PAN fibres. Carbon 1992, 30, 657-663. [CrossRef]

18. Mólnar, K.; Szolnoki, B.; Toldy, A.; Vas, L.M. Thermochemical stabilization and analysis of continuously electrospun nanofibers. J. Anal. Calorim. 2014, 117, 1123-1135. [CrossRef]

19. Wortmann, M.; Frese, N.; Mamun, A.; Trabelsi, M.; Keil, W.; Büker, B.; Javed, A.; Tiemann, M.; Moritzer, E.; Ehrmann, A.; et al. Chemical and Morphological Transition of Poly(acrylonitrile)/Poly(vinylidene Fluoride) Blend Nanofibers during Oxidative Stabilization and Incipient Carbonization. Nanomaterials 2020, 10, 1210. [CrossRef]

20. Wu, S.; Zhang, F.; Yu, Y.H.; Li, P.; Yang, X.P.; Lu, J.G.; Rye, S.K. Preparation of PAN-based carbon nanofibers by hot-stretching. Compos. Interfaces 2008, 15, 671-677. [CrossRef]

21. Wu, M.; Wang, Q.Y.; Li, K.; Wu, Y.Q.; Liu, H.Q. Optimization of stabilization conditions for electrospun polyacrylonitrile nanofibers. Polym. Degrad. Stab. 2012, 97, 1511-1519. [CrossRef]

22. Ma, S.; Liu, J.; Liu, Q.; Liang, J.Y.; Zhao, Y.; Fong, H. Investigation of structural conversion and size effect from stretched bundle of electrospun polyacrylonitrile copolymer nanofibers during oxidative stabilization. Mater. Des. 2016, 95, 387-397. [CrossRef]

23. Ma, S.; Liu, J.; Qu, M.; Wang, X.; Huang, R.; Liang, J. Effects of carbonization tension on the structural and tensile properties of continuous bundles of highly aligned electrospun carbon nanofibers. Mater. Lett. 2016, 183, 369-373. [CrossRef]

24. Santos de Oliveira, M., Jr.; Manzolli Rodrigues, B.V.; Marcuzzo, J.S.; Guerrini, L.M.; Baldan, M.R.; Rezende, M.C. A statistical approach to evaluate the oxidative process of electrospun polyacrylonitrile ultrathin fibers. J. Appl. Polym. Sci. 2017, 134, 45458. [CrossRef]

25. Sabantina, L.; Wehlage, D.; Klöcker, M.; Mamun, A.; Grothe, T.; Rodrígues Mirasol, J.; Cordero, T.; Finsterbusch, K.; Ehrmann, A. Stabilization of electrospun PAN/gelatin nanofiber mats for carbonization. J. Nanomater. 2018, 2018, 6131085. [CrossRef]

26. Sabantina, L.; Rodríguez-Cano, M.Á.; Klöcker, M.; García-Mateos, F.J.; Ternero-Hidalgo, J.J.; Mamun, A.; Beermann, F.; Schwakenberg, M.; Voigt, A.-L.; Rodríguez-Mirasol, J.; et al. Fixing PAN nanofiber mats during stabilization for carbonization and creating novel metal/carbon composites. Polymers 2018, 10, 735. [CrossRef]

27. Storck, J.L.; Grothe, T.; Tuvshinbayar, K.; Diestelhorst, E.; Wehlage, D.; Brockhagen, B.; Wortmann, M.; Frese, N.; Ehrmann, A. Stabilization and incipient carbonization of electrospun polyacrylonitrile nanofibers fixated on aluminum substrates. Fibers $\mathbf{2 0 2 0}$ 8, 55. [CrossRef]

28. Pham, H.H.; Lim, Y.-I.; Cho, C.-H.; Bang, Y.-H. Hydrodynamics of low temperature carbonization furnace for production of polyacrilonitrile (PAN)-based carbon fiber. Chem. Eng. Res. Des. 2017, 128, 192-204. [CrossRef]

29. Youe, W.-J.; Kim, S.J.; Lee, S.-M.; Chun, S.-J.; Kang, J.W.; Kim, Y.S. $\mathrm{MnO}_{2}$-deposited lignin-based carbon nanofiber mats for application as electrodes in symmetric pseudocapacitors. Int. J. Biol. Macromol. 2018, 112, 943-950. [CrossRef]

30. Ma, X.J.; Kolla, P.; Zhao, Y.; Smirnova, A.L.; Fong, H. Electrospun lignin-derived carbon nanofiber mats surface-decorated with $\mathrm{MnO}_{2}$ nanowhiskers as binder-free supercapacitor electrodes with high performance. J. Power Sources 2016, 325, 541-548. [CrossRef]

31. Dimesso, L.; Spanheimer, C.; Jaegermann, W.; Zhang, Y.; Yarin, A.L. LiCoPO 4 -3D carbon nanofiber composites as possible cathode materials for high voltage applications. Electrochim. Acta 2013, 95, 38-42. [CrossRef]

32. Tolosa, A.; Fleischmann, S.; Grobelsek, I.; Quade, A.; Lim, E.; Presser, V. Binder-free hybrid titanium-niobium oxide/carbon nanofiber mats for lithium-ion battery electrodes. ChemSusChem 2018, 11, 159-170. [CrossRef] [PubMed]

33. Kim, Y.K.; Kim, M.S.; Hwang, S.-H.; Lim, S.K.; Park, H.W.; Kim, S.H. CdS-loaded flexible carbon nanofiber mats as a platform for solar hydrogen production. Int. J. Hydrog. Energy 2015, 40, 136-145. [CrossRef]

34. Lai, C.L.; Kolla, P.; Zhao, Y.; Fong, H.; Smirnova, A.L. Lignin-derived electrospun carbon nanofiber rmats with supercritically deposited Ag nanoparticles for oxygen reduction reaction in alkaline fuel cells. Electrochim. Acta 2014, 130, 431-438. [CrossRef]

35. Wortmann, M.; Layland, A.S.; Frese, N.; Kahmann, U.; Grothe, T.; Storck, J.L.; Blachowicz, T.; Grzybowski, J.; Hüsgen, B.; Ehrmann, A. On the reliability of highly magnified micrographs for structural analysis in materials science. Sci. Rep. 2020, 10, 14708. [CrossRef] [PubMed] 